\title{
Ethylene-Cytokinin Interaction Determines Early Defense Response of Wheat against Stagonospora nodorum Berk.
}

\author{
Svetlana V. Veselova ${ }^{1, *}$, Tatyana V. Nuzhnaya ${ }^{1,2} \mathbb{C}^{-}$, Guzel F. Burkhanova ${ }^{1}{ }^{\complement}$, Sergey D. Rumyantsev ${ }^{1}{ }^{(}$, \\ Elza K. Khusnutdinova ${ }^{1}$ and Igor V. Maksimov ${ }^{1}$ \\ 1 Institute of Biochemistry and Genetics, Ufa Federal Research Centre, Russian Academy of Sciences, \\ Prospekt Oktyabrya, 71, 450054 Ufa, Russia; tanyawww89@mail.ru (T.V.N.); guzel_mur@mail.ru (G.F.B.); \\ rumyantsev-serg@mail.ru (S.D.R.); elzakh@mail.ru (E.K.K.); igor.mak2011@yandex.ru (I.V.M.) \\ 2 Ufa Institute of Biology, Ufa Federal Research Centre, Russian Academy of Sciences, Prospekt Oktyabrya, 69 \\ 450054 Ufa, Russia \\ * Correspondence: veselova75@rambler.ru; Tel.: +7-9173423941
}

Citation: Veselova, S.V.; Nuzhnaya, T.V.; Burkhanova, G.F.; Rumyantsev, S.D.; Khusnutdinova, E.K.; Maksimov, I.V. Ethylene-Cytokinin Interaction Determines Early Defense Response of Wheat against Stagonospora nodorum Berk. Biomolecules 2021, 11, 174. https://doi.org/10.3390/ biom11020174

Academic Editor: Guzel Kudoyarova Received: 31 December 2020

Accepted: 24 January 2021

Published: 28 January 2021

Publisher's Note: MDPI stays neutral with regard to jurisdictional claims in published maps and institutional affiliations.

Copyright: (c) 2021 by the authors. Licensee MDPI, Basel, Switzerland. This article is an open access article distributed under the terms and conditions of the Creative Commons Attribution (CC BY) license (https:/ / creativecommons.org/licenses/by/ $4.0 /)$.

\begin{abstract}
Ethylene, salicylic acid (SA), and jasmonic acid are the key phytohormones involved in plant immunity, and other plant hormones have been demonstrated to interact with them. The classic phytohormone cytokinins are important participants of plant defense signaling. Crosstalk between ethylene and cytokinins has not been sufficiently studied as an aspect of plant immunity and is addressed in the present research. We compared expression of the genes responsible for hormonal metabolism and signaling in wheat cultivars differing in resistance to Stagonospora nodorum in response to their infection with fungal isolates, whose virulence depends on the presence of the necrotrophic effector SnTox3. Furthermore, we studied the action of the exogenous cytokinins, ethephon (2-chloroethylphosphonic acid, ethylene-releasing agent) and 1-methylcyclopropene (1-MCP, inhibitor of ethylene action) on infected plants. Wheat susceptibility was shown to develop due to suppression of reactive oxygen species production and decreased content of active cytokinins brought about by SnTox3-mediated activation of the ethylene signaling pathway. SnTox3 decreased cytokinin content most quickly by its activated glucosylation in an ethylene-dependent manner and, furthermore, by oxidative degradation and inhibition of biosynthesis in ethylene-dependent and ethylene-independent manners. Exogenous zeatin application enhanced wheat resistance against S. nodorum through inhibition of the ethylene signaling pathway and upregulation of SA-dependent genes. Thus, ethylene inhibited triggering of SA-dependent resistance mechanism, at least in part, by suppression of the cytokinin signaling pathway.
\end{abstract}

Keywords: plant-microbe interaction; Stagonospora nodorum; necrotrophic effectors; SnTox3; ethylene; cytokinins; crosstalk; reactive oxygen species; NADPH oxidases

\section{Introduction}

In natural growing conditions, plants are permanently in contact with pathogens and respond to their attacks by activating defense mechanisms regulated by a number of interacting signals [1,2]. The current model of the plant immune system proposes that host defenses are opposed to counterattacks by pathogens at several levels [3]. The plant initially identifies pathogen-associated molecular patterns (PAMPs) by pattern recognition receptors (PRRs), leading to the development of basal immunity, known as pattern triggered immunity (PTI) [3]. To overcome PTI and the subsequent defense signaling, pathogens have developed molecules known as effectors, which induce an effector-triggered susceptibility (ETS) [3]. Effectors are directly or indirectly recognized by products of effector-specific resistance genes, which often encode intercellular proteins called nucleotide binding domain and leucine-rich repeat domain proteins. This recognition results in development of effector-triggered immunity (ETI) in biotrophic pathogens [3]. Until recently, very little was known about how plants struggle with necrotrophic pathogens, which, in contrast 
to biotrophs, obtain nutrients from dead tissue [4]. However, recent studies have revealed that some necrotrophic fungal pathogens produced effector proteins also known as host-selective toxins (HSTs) or necrotrophic effectors (NEs) that interact either directly or indirectly with dominant sensitivity/susceptibility gene products to induce disease [5]. Thus, NEs suppress PTI and use the host's ETI pathway to develop sensitivity, resulting in NE-triggered susceptibility (NETS) [5,6].

Numerous fungal NEs encoded by SnTox genes are the most important virulence factors of pathogenic fungus Stagonospora nodorum Berk. (syn. Septoria, Parastagonospora; teleo, Phaeosphaeria), the causative agent of Septoria nodorum blotch (SNB) in wheat $[7,8]$. The interaction in the wheat-S. nodorum pathosystem is of the gene-for-gene type [8]. The products of the virulence genes of pathogens (=necrotrophic effectors or host-specific toxins) (SnTox) interact with the products of the susceptibility genes of the host plants (Snn) followed by disease development [7]. To date, three effector genes have been identified in the genome of S. nodorum (SnToxA, SnTox1, SnTox3) [7]. The effectors, SnToxA, SnTox1, and SnTox3, are quite widespread among strains and isolates and are considered to be the main ones in the pathogen S. nodorum [9]. The effectors, SnToxA, SnTox1, and SnTox3, cause necrosis and chlorosis in susceptible wheat genotypes and affect redox metabolism of the host plant [8]. In addition, the role of NEs SnToxA, SnTox1, and SnTox3 in the suppression of PTI and the development of NETS is expected [8].

The development of PTI induces multiple cellular responses, including the generation of reactive oxygen species (ROS) and calcium-dependent or mitogen-activated protein kinase cascade activation, which subsequently leads to the reprogramming of the transcriptome and proteome [10]. Phytohormones play a key regulatory role in these primary immune responses upon activation of PTI. Salicylic acid (SA), jasmonic acid (JA), and ethylene are considered to be the classical plant hormones of immunity [1]. These phytohormones constitute the central regulatory network of plant immunity and interact with growth-related plant hormones such as cytokinins (CKs), auxins, abscisic acid (ABA), brassinosteroids (BRs), and gibberellins (GAs) [1,11].

Ethylene is a plant hormone that not only regulates the processes of plant growth and development, but it is also one of the main phytohormones of plant immunity. However, the role of ethylenein plant defense is ambiguous. It has been shown that activation of the ethylene signaling pathway can lead to both resistance and susceptibility of plants to pathogens $[12,13]$. It has been suggested that ethylene acts as a positive or negative inducer of resistance depending on the type of pathogen and is a regulator of the interaction between SA- and JA-dependent defense reactions [14]. Crosstalk among different hormonal networks is often observed in plant immunity. The antagonistic nature of the crosstalk between the SA and JA pathways was the first to be shown in plant immune responses [15]. Then, synergism between JA and ethylene, and antagonism between SA and ethylene pathways were also revealed in various pathosystems [11,16]. However, to date, the role of ethylene itself, as well as its relationship with other phytohormones, especially with CKs, in plant-microbe interactions, remains largely uncharacterized.

Recently, the important role of the classical phytohormone CK has been revealed in the development of plant resistance through the regulation of SA-dependent defense reactions, induction of the gene expression of protective proteins, phytoalexins synthesis, and lignification processes [17-20]. Thus, CK-ABA antagonism has been identify in tobacco as a novel regulatory mechanism to modulate resistance against Pseudomonas syringae [19]. Unfortunately, the interaction of ethylene and CK has been studied only in the regulation of growth and development processes [21,22] and in response to abiotic stress factors [21,23], where an antagonistic relationship has been shown between $\mathrm{CK}$ and ethylene. Thus, questions regarding the nature of the interaction between ethylene and CK remain open when it comes to plant immunity.

The mechanisms underlying hormonal crosstalk are not fully understood. However, there is a widespread opinion that signaling proteins, such as Nonexpressor of PR Genes1 (NPR1), DELLA, Arabidopsis Response Regulator (ARR), Ethylene Insensitive3 (EIN3) and 
Ethylene Insensitive3-Like1 (EIL1), transcription factors of WRKY family (transcription factors of WRKY family that contain WRKY domains at the N-terminus, having a conserved heptapeptide sequence WRKYGQK, and a zinc-finger-like motif at the C-terminus) and others, can be considered as hormone crosstalk hubs [11]. Frequently, the same signaling proteins involved in hormonal crosstalk are the targets of the effectors [24]. Effectors secreted by pathogens and providing successful plant colonization by suppressing PTI interfere with the pathways of phytohormones [24]. Manipulation of hormonal pathways by effectors occurs at different levels. Effectors can affect phytohormone biosynthesis or important components of hormonal signaling pathways [24]. SnTox3 has been shown relatively recently to activate biosynthesis of ethylene in plants [25] and further more SnToxA and SnTox3 directly interacted with the PR-1 protein and enhanced the infection of wheat by $S$. nodorum [26].

We have previously shown that ethylene provided favorable conditions for the penetration and growth of S. nodorum in the tissues of wheat plants at the initial stage of infection due to the regulation of redox metabolism and a decrease in the generation of $\mathrm{H}_{2} \mathrm{O}_{2}$ [27], and development of the wheat plants resistance against $S$. nodorum was accompanied by an increase in the zeatin content in the leaves [28]. Here, we address the early signaling events in wheat responding to the S. nodorum and analyze the role of NE SnTox3 in the suppression of the PTI reaction such as ROS production. To achieve this, we employed an integrated approach using real-time qPCR, ELISA and microscopy methods. We demonstrated that NE SnTox3 induced an ethylene signaling pathway and inhibited biosynthesis, modulated metabolism, and activated oxidative degradation of CKs to regulate ROS production in wheat at the early stages of $S$. nodorum infection. Our results suggest that antagonism of ethylene and CK is directed to the regulation of SA-dependent defense reactions responsible for the development of PTI and early wheat resistance against S. nodorum. In addition, we provide novel evidence regarding the role of the CK as a crucial regulator of plant immunity. These findings are useful for understanding the mechanisms underlying the manipulation of plant hormonal signaling pathways by pathogen effectors during the suppression of PTI and the development of ETS (NETS).

\section{Materials and Methods}

\subsection{Plant and Fungi Materials and Growth Conditions}

The objects of the study were two cultivars of common wheat (Triticum aestivum L.) contrasting in resistance to S. nodorum Berk.: Omskaya 35 (Om35) (resistant) and Kazakhstanskaya 10 (Kaz10) (susceptible), with different allelic states of the susceptibility locus Snn3-B1 [29]. Wheat seeds were obtained from the Bashkir scientific research Institute of Agriculture of Russian Agricultural Academy. We used two isolates of the fungus S. nodorum: Sn4VD (avirulent) and SnB (virulent) (from the collection of Institute of Biochemistry and Genetics, Ufa Federal Research Centre, Russian Academy of Sciences, Ufa, Russia). All S. nodorum isolates were maintained on potato-glucose agar (PGA) at $21^{\circ} \mathrm{C}$ for a $12 \mathrm{~h}$ photoperiod. Plants were hydroponically grown on $10 \%$ solution of HoaglandArnon nutrient medium in a KS-200 SPU growth chamber (Russia) at $20 / 24^{\circ} \mathrm{C}$ (night/day) at an irradiance of $146 \mathrm{~W} / \mathrm{m}^{2}$ FAR (Osram lamps L $36 \mathrm{~W} / 77$, Osram Licht AG, Munich, Germany) and with a $16 \mathrm{~h}$ photoperiod for six days.

\subsection{Experimental Design}

All experiments were carried out on intact six-day-old seedlings, with the exception of experiments evaluating the resistance of genotypes, which were performed on the separated first leaves by the lawns method [27]. In some cases, parts of 6-days-old seedlings placed in separate vessels were sprayed with $2 \mathrm{mM}$ solution of 1-methylcyclopropene (1-MCP) to study the role of ethylene. The compound was prepared from its SmartFresh precursor (AgroFresh Inc., Philadelphia, PA, USA). The procedure was performed no later than $5 \mathrm{~min}$ after preparing the solution when gaseous 1-MCP arose [30]. Other plants were sprayed with $1.5 \mathrm{mM}$ solution of 2-chloroethylphosphonic acid (ethephone, 
ET) (Merck KGaA, Sigma-Aldrich, Darmstadt, Germany) in separate vessels [31]. To study the role of cytokinins, parts of 6-day-old seedlings were sprayed with $2.5 \mu \mathrm{M}$ solution of trans-zeatin (Merck KGaA, Sigma-Aldrich, Darmstadt, Germany). The immunestimulating concentration of trans-zeatin was selected according to [32]. All solutions contained the wetting agent Tween-20 $(0.02 \%)$. Control plants were sprayed with a solution containing only the wetting agent Tween-20 $(0.02 \%)$. The volumes of all solutions allowed full moistening of leaves. In all cases, vessels were closed with caps and transferred into the darkness. During the experiments by the lawns method, the first leaves of the 6-day-old seedlings were separated and placed in Petri dishes on wet cotton wool containing $0.004 \%$ benzamidazole (10-12 leaves / dish) [27]. Then, leaves were sprayed with 1-MCP, ET, or trans-zeatin, and the Petri dishes were covered and placed in the darkness. All treatments were performed $24 \mathrm{~h}$ prior to inoculation with S. nodorum isolates. In the case of studying the role of salicylic acid (SA), a presowing treatment was performed by soaking the seeds for $3 \mathrm{~h}$ in a $0.05 \mathrm{mM}$ SA solution (Merck KGaA, Sigma-Aldrich, Darmstadt, Germany). Then, the plants were grown as described above. The biologically effective concentration of SA was selected according to [33-35].

To study the effect of the necrotrophic effector SnTox3, two S. nodorum isolates were used. Previously, it was shown that the virulent isolate SnB expressed SnTox3 and caused severe damage in susceptible genotypes [29]. Avirulent isolate Sn4VD did not express SnTox3 and did not cause significant damage in both resistant and susceptible genotypes [29]. After the treatments described above, seedlings were either sprayed with a spore suspension of S. nodorum isolates with the addition of a wetting agent Tween-20 $(0.02 \%)$, or the drops of the fungal spore suspension were applied to the separated leaves in the amount of $5 \mu \mathrm{L}$ per leaf. Concentration of suspension was $1 \times 10^{6}$ spores $\mathrm{mL}^{-1}$ in both cases. Then, the vessels with seedlings and Petri dishes with the separated leaves were closed with caps and transferred to the controlled conditions of the growth chamber. The development of SNB symptoms was observed on separated wheat leaves placed in Petri dishes for 8 days. The lesion areas were registered using an SP-800UZ Image Stabilization camera (Olympus, Bekasi, Indonesia) on the eighth day. The damage zones were measured with the ImageJ 1.44 computer program (rsbweb.nih.gov/ij/download.html) and expressed as a percentage of the total leaf area.

To study biochemical characteristics, the shoots of intact wheat seedlings that underwent various treatments were fixed in liquid nitrogen 1, 6, 12, 24, 48 and $72 \mathrm{~h}$ after inoculation with $S$. nodorum virulent isolate $\mathrm{SnB}$. To study gene expressions, the shoots of intact wheat seedlings were fixed in liquid nitrogen 6 and $24 \mathrm{~h}$ after inoculation with S. nodorum isolates $\mathrm{SnB}$ and $\mathrm{Sn} 4 \mathrm{VD}$. In the case of studying the transcriptional activity of the TaWRKY13 and TaRR21 genes, plants were fixed $15 \mathrm{~min}, 3$, and $6 \mathrm{~h}$ after inoculation with S. nodorum virulent isolate SnB. Cytokinins were quantified in shoots $24 \mathrm{~h}$ after inoculation with S. nodorum isolates SnB and Sn4VD using an enzyme-linked immunosorbent assay (ELISA) after their solvent partitioning and purification. The variants of treatments and the number of repetitions are indicated in the tables and figures.

\subsection{Isolation of RNA and Performing the Quantitative Real-Time Polymerase Chain Reaction ( $q P C R$ )}

Total wheat RNA was extracted using TRIzol ${ }^{\mathrm{TM}}$ Reagent (Sigma, Germany) according to the manufacturer's instructions. The potential contaminating DNA was digested with DNaseI (Synthol, Moscow, Russia). First-strand cDNA was synthesized using the M-MLV reverse transcriptase (Fermentas). Oligo(dT)15 was used as a primer, and the reverse transcription reagents were incubated at $37^{\circ} \mathrm{C}$ for $1 \mathrm{~h}$ in a total volume of $25 \mu \mathrm{L}$. After tenfold dilution, $2 \mu \mathrm{L}$ of the synthesized cDNA was used for quantitative real-time polymerase chain reaction (qPCR). The primers for $\mathrm{qPCR}$ were designed based on the cDNA sequence (Table S1, see Supplementary Materials). Quantitative PCR was performed by polymerase chain reaction in real time using a set of predefined reagents, EvaGreenI (Synthol, Moscow, Russia), and a CFX Connect real-time PCR Detection System device (BioRad Laboratories, Hercules, CA, USA). The qPCR program was as follows: $95^{\circ} \mathrm{C}$ for $5 \mathrm{~min} ; 40$ cycles of $95^{\circ} \mathrm{C}$ 
for $15 \mathrm{~s}, 60^{\circ} \mathrm{C}$ for $20 \mathrm{~s}$, and $72{ }^{\circ} \mathrm{C} 30 \mathrm{~s}$. After the final PCR cycle, a melting curve analysis was conducted to determine the specificity of the reaction (at $95^{\circ} \mathrm{C}$ for $15 \mathrm{~s}, 60^{\circ} \mathrm{C}$ for $1 \mathrm{~min}$, and $95^{\circ} \mathrm{C}$ for $15 \mathrm{~s}$ ). The efficiency of each primer pair was determined using 10-fold cDNA dilution series in order to reliably determine the fold changes. To standardize the data, wheat gene TaRLI (RNaseL inhibitor-like) (GenBank Accession No. AY059462) was used as an internal reference for the real-time qPCR analysis. The quantification of gene expression was performed using a CFX Connect real-time PCR Detection System (BioRad Laboratories, USA). All reactions, including the nontemplate control, were performed three times. The threshold values (CT) generated from the CFX Connect real-time PCR Detection System software tool (Applied Biosystems, Foster City, CA, USA) were employed to quantify the relative gene expression using the comparative threshold (delta CT) method. Three independent biological replicates were performed for each experiment.

\subsection{Biochemical Parameters}

To measure the hydrogen peroxide $\left(\mathrm{H}_{2} \mathrm{O}_{2}\right)$ production and the activity of redox enzymes (peroxidase (POD) and catalase (CAT)), plant material (1:5 weight/volume) was fixed in liquid nitrogen and then it was homogenized in $0.05 \mathrm{M}$ solution of Na-phosphate buffer (PB), pH 6.2 and incubated at $4{ }^{\circ} \mathrm{C}$ for $30 \mathrm{~min}$. Supernatants were separated by centrifugation at $15,000 \times g$ for $15 \mathrm{~min}$ ( $5415 \mathrm{~K}$ Eppendorf, Hamburg, Germany). Concentration of $\mathrm{H}_{2} \mathrm{O}_{2}$ in the supernatant was determined using xylenol orange in the presence of $\mathrm{Fe}^{2+}$ at $560 \mathrm{~nm}$ by the method of [36]. POD activity was determined by a micromethod in 96 -well plates (Corning-Costar, Glendale, AZ, USA) by the oxidation of (o-) phenylenediamine in the presence of $\mathrm{H}_{2} \mathrm{O}_{2}$ at $490 \mathrm{~nm}$ on a Benchmark Microplate Reader spectrophotometer (Bio-Rad Laboratories, Hercules, CA, USA) [27]. The enzyme activity was expressed in optical density/mg protein per minute. CAT activity was determined by a micromethod based on the ability of $\mathrm{H}_{2} \mathrm{O}_{2}$ to form a stable colored complex with molybdate salts [27]. Optical density was measured at $405 \mathrm{~nm}$ on a Benchmark Microplate Reader spectrophotometer. CAT activity was calculated using a calibration curve and expressed in $\mu \mathrm{M} \mathrm{H}_{2} \mathrm{O}_{2} /(\mathrm{mg}$ protein per min). Protein content was determined by the Bradford method.

\subsection{Visualization of $\mathrm{H}_{2} \mathrm{O}_{2}$, Superoxide Radical, and Fungal Mycelium in Wheat Tissues}

The local generation of superoxide radicals and $\mathrm{H}_{2} \mathrm{O}_{2}$ in infected leaf tissues was determined by vital staining with solutions of nitroblue tetrazolium (NBT) $(0.1 \%)$ (Sigma, Germany) and diaminobenzidine (DAB) $\left(1 \mathrm{mg} \mathrm{mL}^{-1}\right)$ (Sigma, Germany), respectively, prepared as described in [12,37-39]. For this purpose, 6 and $24 \mathrm{~h}$ after inoculation with S. nodorum, leaf sections were incubated in vacuum for $60 \mathrm{~min}$ at $20^{\circ} \mathrm{C}$, and then the leaves were fixed in $96 \%$ ethanol and transferred into a $50 \%$ glycerol solution. To visualize the mycelium of S. nodorum, $24 \mathrm{~h}$ after inoculation with the pathogen leaf sections were fixed in $96 \%$ ethanol and then stained with $1.0 \%$ aniline blue solution in $1 \%$ lactic acid. As a result, the structures of the fungus became blue-violet [39]. To register the accumulation of superoxide radical and $\mathrm{H}_{2} \mathrm{O}_{2}$ and the development of the pathogen mycelium, a BZ8100E digital microscope (Keyence, Osaka, Japan) was used.

\subsection{Determination of Cytokinines}

Shoots of ten plants (approximately $1 \mathrm{~g}$ ) per one biological replication were homogenized and cytokinins were extracted with 80\% ethanol (1:10, weight/volume) for $16 \mathrm{~h}$ at $4{ }^{\circ} \mathrm{C}$. The extract was separated by 20-min centrifugation at $4000 \times g$ in an Avanti J-E centrifuge (Bekman Coulter, Bray, CA, USA) and evaporated to obtain aqueous residue. Different forms of cytokinins present in an aliquot of aqueous residue were concentrated on a C18 column (Waters Corporation, Milford, MA, USA), eluted with $5 \mathrm{~mL}$ of $80 \%$ ethanol and then evaporated to dryness. Cytokinin bases and their derivatives from the dry residue were separated by thin layer chromatography on silufol plates (Merck KGaA, Fluka, Darmstadt, Germany) in the system of solvents butanol: ammonium hydrate: water (6:1:2) according to the work of [40]. This procedure enabled separation and assay of cytokinin 
nucleotide (Rf 0-0.1), cytokinin glucosides ( $\mathrm{Rf} 0.1-0.2)$, riboside of zeatin (ZR, Rf 0.4-0.5), isopentenyladenosine (iPA, $\mathrm{Rf} 0.5-0.6)$, zeatin ( $\mathrm{Z}, \mathrm{Rf} 0.6-0.7)$, and isopentenyladenine (iP, Rf 0.7-0.8). The material from different zones was eluted with $0.1 \mathrm{M} \mathrm{PB}, \mathrm{pH} 7.4$ for $16 \mathrm{~h}$. Then, silica gel was removed by 10 -min centrifugation at $10,000 \times g$ in an Eppendorf $5415 \mathrm{~K}$ centrifuge. In the supernatant, phytohormone was assayed by means of ELISA as earlier described using specific antibodies [40]. Anti-trans-ZR and anti-iPA sera were used for the assay of cytokinins of $Z$ and iP types, correspondingly [40]. Their specificity has been described previously $[40,41]$. Since O-glucosides have very low affinity to the antibodies used in this work, treatment with $\beta$-glucosidase $(0.02 \mathrm{mg}$ enzyme from Sigma, USA per milliliter sample from $0.5 \mathrm{~g}$ of fresh leaves) was carried out for $4 \mathrm{~h}$ at $37^{\circ} \mathrm{C}, \mathrm{pH} 5.0$, to release immunoreactive zeatin for zeatin glucoside quantification as described [42]. The reliability of the hormone immunoassay has been confirmed using a dilution test and through comparison with the data obtained with the results of high performance liquid chromatography (HPLC) in combination with mass spectrometry [40,42].

\subsection{Statistics}

Experiments were performed three times with three replicates for each treatment, except for the measurements of infected areas, which were performed in no less than 30 biological replications for each experiment. One replicate contained shoots of ten plants in the case of ELISA, and it contained shoots of five plants in the case of qPCR and biochemical assay of enzyme activity and $\mathrm{H}_{2} \mathrm{O}_{2}$ production. Leaf segments of ten plants were fixed for each treatment for histochemical localization of $\mathrm{H}_{2} \mathrm{O}_{2}$ and superoxide radicals. Microphotographs represent results of a typical variant from a series of experiments. Experimental data were expressed as means $\pm \mathrm{SE}$, which were calculated in all treatments using MS Excel. Analysis of variance (ANOVA) was used to calculate the least significance difference (LSD) at $p<0.05$ to discriminate means.

\section{Results}

3.1. Biosynthesis and Signaling Pathway of Ethylene in Wheat Is Activated by the Effector Stagonospora nodorum Berk

The Om35 and Kaz10 cultivars were selected as the SnTox3-insensitive and SnTox3sensitive cultivars, respectively. Plants were inoculated with two $S$. nodorum isolates, one was virulent, expressing SnTox3 (SnB) and the other was avirulent and did not express SnTox3 (Sn4VD) [29]. An incompatible interaction or resistance reaction was detected when the SnTox3-insensitive cultivar, Om35, was inoculated with a virulent isolate SnB or when cultivars Om35 and Kaz10 were inoculated with an avirulent isolate, Sn4VD. A compatible interaction or susceptibility response was developed when the SnTox3-sensitive cultivar Kaz10 was inoculated with a virulent isolate SnB. Compatible interaction (Kaz10/SnB) was characterized by the development of extensive lesion zones, covering up to $70 \%$ of the total leaf area, with typical spots of chlorosis and necrosis with numerous pycnidia, which are organs of asexual reproduction (Figure 1). In all incompatible interactions (Om35/SnB, Kaz10/Sn4VD, Om35/Sn4VD), the coverage of damage zones was from 0.5 to $12 \%$ of the total leaf area and these were characterized by the absence of mycelium, pycnidia, and chlorosis and consisted of necrotic zones, which may indicate a cessation of pathogen growth (Figure 1).

Pretreatment of plants with ET increased the virulence of the isolate SnB in both Kaz10 and Om35 cultivars. The reaction of cultivar Om35 to SnB was similar to the reaction of cultivar Kaz10 with this isolate; the damage of leaf zones was up to $70 \%$ of the total area, but there was less chlorosis and pycnidia than in the Kaz10 response to SnB infection (Figure 1). In the Kaz10/SnB/ET combination, large lesion areas with active sporulation of the pathogen were detected, covering up to $90 \%$ of the total leaf area (Figure 1).

Pretreatment of plants with ET did not increase the virulence of the isolate Sn4VD. Pretreatment of plants with 1-MCP reduced the virulence of the SnB isolate on both Kaz10 and Om35 cultivars, but to a greater extent on the Kaz10 variety (Figure 1). In the 
Kaz10/SnB/1-MCP and Om35/SnB/1-MCP combinations, minimal lesions with small necrosis were found. The proportion of area damaged per leaf was about $2 \%$. Pretreatment of plants with 1-MCP did not affect the virulence of the isolate Sn4VD (Figure 1). These results show the negative role of ethylene in the development of wheat resistance against S. nodorum due to the sensitivity of the host plant to the NE SnTox3 and the connection of SnTox3 with the ethylene signaling pathway.
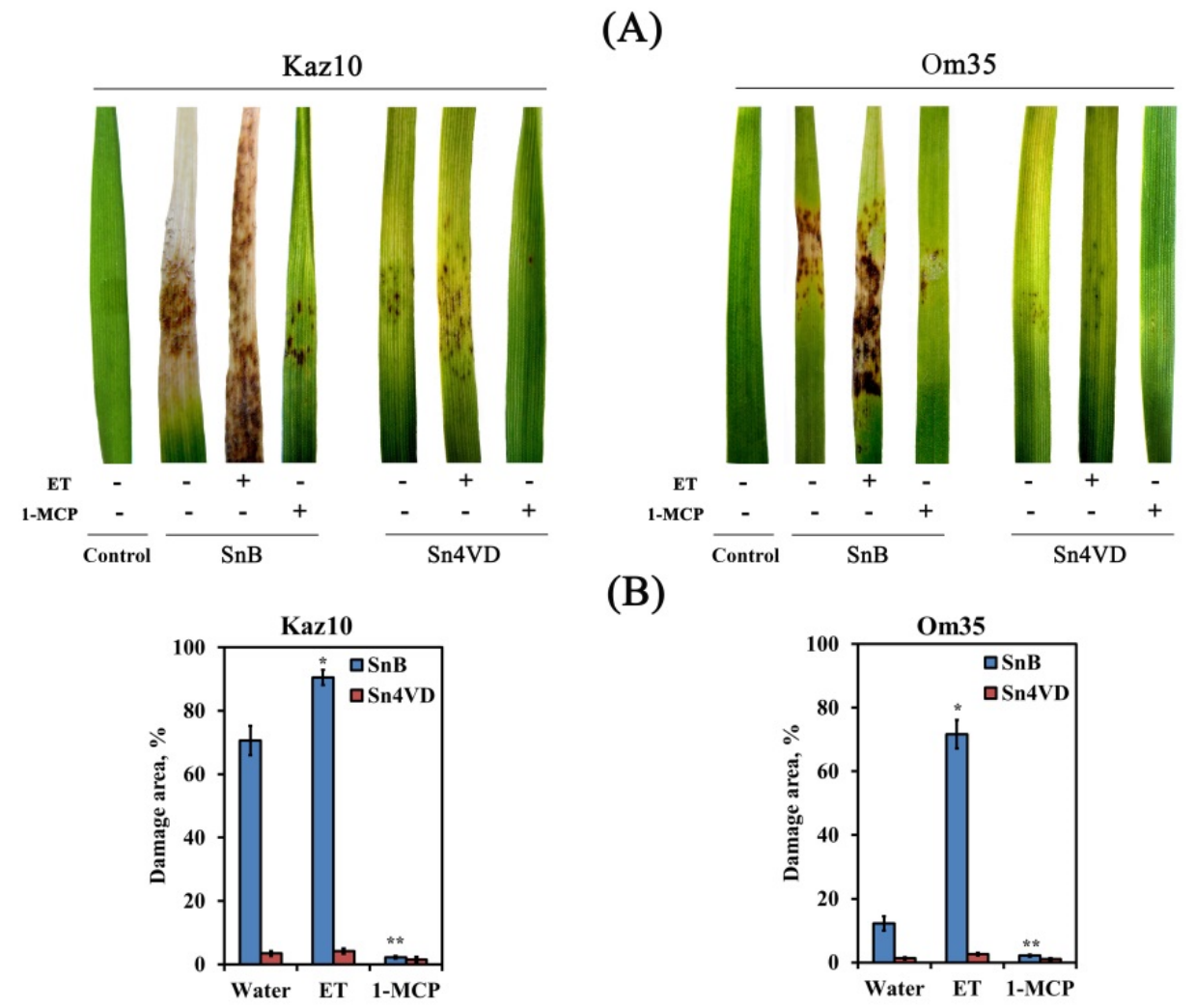

(B)

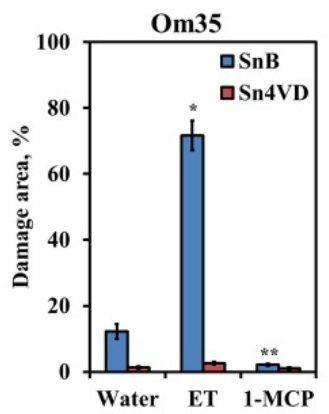

Figure 1. Reaction of Kazakhstanskaya 10 (Kaz10) and Omskaya 35 (Om35) wheat cultivars when inoculaed with virulent SnB and avirulent Sn4VD S. nodorum isolates after treatment with either ethephone (ET) or 1-methylcyclopropene (1-MCP). (A) Septoria nodorum blotch symptoms 8 days after inoculation. Photographs represent results of a typical variant from a series of experiments. (B) Damage zones on the leaves of Kaz10 and Om35 on the eighth day of inoculation, expressed as percent of the total leaf area. The samples are indicated as follows: Control—plants that have neither been treated nor inoculated with $S$. nodorum isolates; water-plants that have been sprayed with water; ET—-plants that have been treated with ethephone (ET), releasing ethylene; 1-MCPplants that have been treated with 1-methylcyclopropene (1-MCP), which is able to bind to ethylene receptors to block ethylene perception of. Figures present means $\pm S E(n=30)$. Asterisks indicate means statistically different from the plants infected with $S$. nodorum without any pretreatments and different number of asterisks $\left({ }^{*}\right.$ and ${ }^{* *}$ ) allows distinguishing of significantly different variants according to the LSD test at ${ }^{*} p<0.05,{ }^{* *} p<0.01$.

To check the effect of NE SnTox3 on the biosynthesis and signaling pathway of ethylene in plants, both cultivars Kaz10 and Om35 were pretreated with either ET or 1-MCP and were inoculated with the isolate $\mathrm{SnB}$. We studied the expression of genes involved in ethylene biosynthesis (aminocyclopropane (ACC) synthase (TaACS1) and ACC oxidase $(\mathrm{TaACO})$ ), as well as genes of the ethylene signaling pathway (TaEIL1 and TaPIE1) (Figure 2). The gene of transcription factor (TF) TaEIL1 (Ethylene-Insensitive3-Like1-EIN3-Like1) is an orthologue of the Arabidopsis gene AtEIN3 encoding the main regulatory factor of ethylene signaling. The gene of TF Pathogen-Induced ERF1 (TaPIE1) is an orthologue of the 
Arabidopsis gene AtERF1, which is involved in the primary response to ethylene, regulating the expression of second-order regulatory genes (Table S2, see Supplementary Materials).

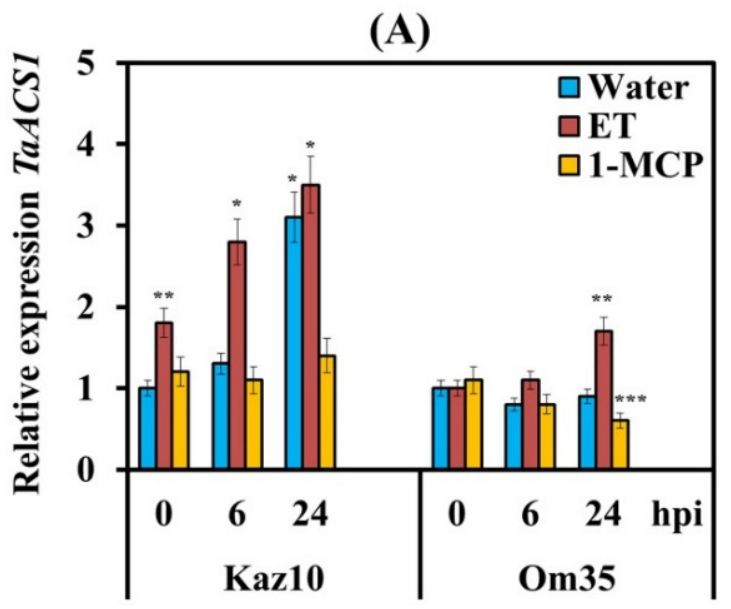

(C)

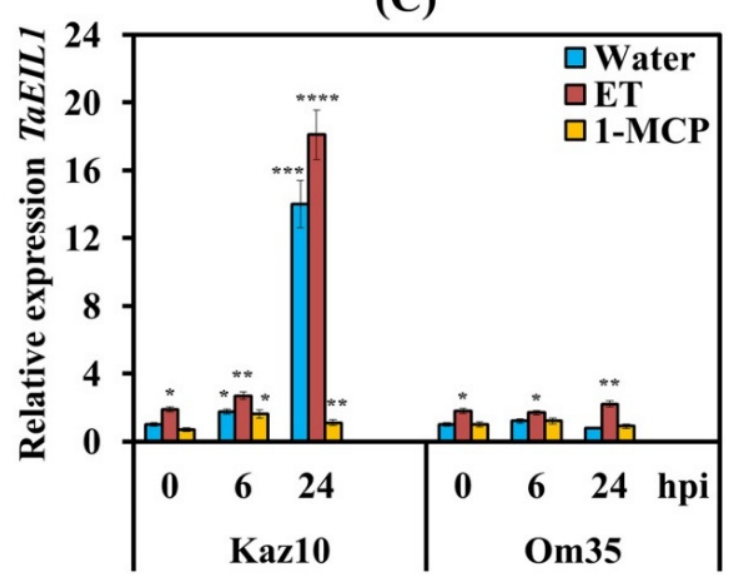

(B)

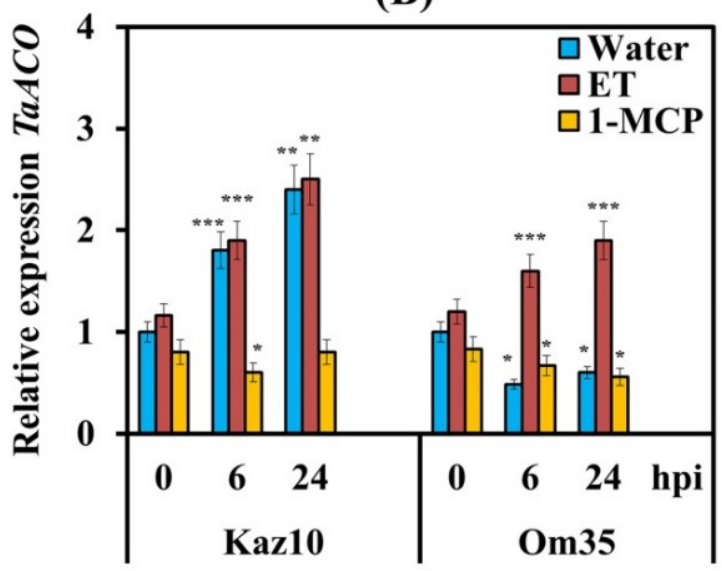

(D)

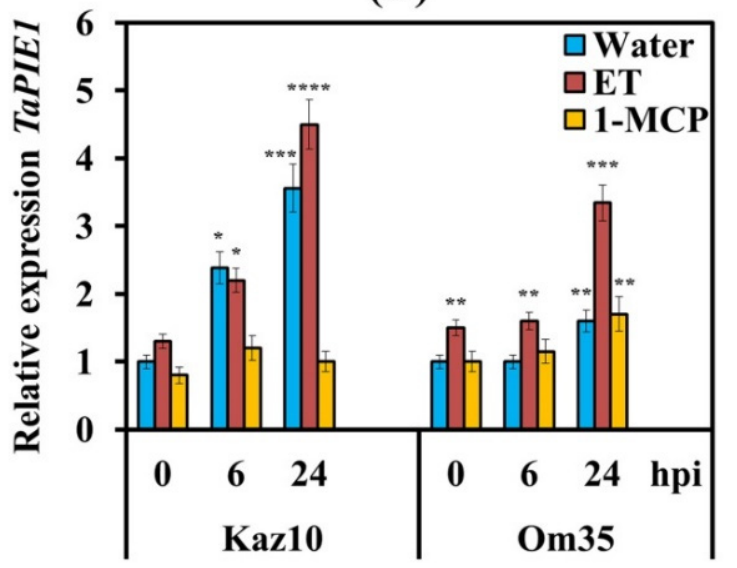

Figure 2. Pretreatment with ethephone (ET) upregulated and pretreatment with 1-MCP downregulated the relative expression of genes involved in the biosynthesis and signaling pathway of ethylene at the early stages of infection of Kaz10 and Om35 wheat cultivars infected with SnB. (A) The mRNA level of the TaACS1 gene. (B) TaACO gene. (C) TaEIL1 gene. (D) TaPIE1 gene. Expression values were normalized to the housekeeping gene TaRLI as an internal reference and expressed relative to the normalized expression levels in mock-treated control (water) plants at 0 hpi. The samples are indicated as follows: water-noninfected plants (0 hpi) or plants infected with the S. nodorum, sprayed in water; ET-noninfected plants (0 hpi) or plants infected with S. nodorum, treated with ethephone (ET); 1-MCP-uninfected plants (0 hpi) or plants infected with $S$. nodorum, treated with 1-methylcyclopropene (1-MCP). Figures present means $\pm \mathrm{SE}(\mathrm{n}=6)$. Asterisks indicate means statistically different from the control and different number of asterisks $\left({ }^{*}, * *, * * *, * * *\right)$ allows distinguishing of significantly different variants according to the LSD test at ${ }^{*} p<0.05,{ }^{* *} p<0.01,{ }^{* * *} p<0.001,{ }^{* * * *} p<0.0001$.

Analysis of the transcriptional activity of the TaACS, TaACO, TaEIL1, and TaPIE1 genes showed an increase in the mRNA abundance of these genes in the SnTox3-sensitive variety Kaz10 and in plants treated with ET (Kaz10/SnB/ET, Om35/SnB/ET) (Figure 2). In SnTox3-sensitive plants, Kaz10 the transcript levels of ethylene biosynthesis genes TaACS, TaACO, and the TaPIE1 gene increased approximately 3-4 times, and the mRNA abundance of the TaEIL1 gene increased 14-18 times at 24 hpi (Figure 2).

Interestingly, the accumulation of mRNA of genes responsible for ethylene biosynthesis and signaling pathway in SnTox3-insensitive plants in the Om35/SnB/ET combination was lower than that in SnTox3-sensitive plants; the transcript levels of all genes increased only from 1.5 to 3 times at 24 hpi (Figure 2). These results show that the induction of the 
ethylene signaling pathway was strongly dependent on gene-for-gene interactions. In plants treated with 1-MCP, both SnTox3-sensitive (Kaz10) and SnTox3-insensitive (Om35), suppression of transcript accumulation of ethylene biosynthesis and signaling pathway genes was found (Figure 2).

3.2. SnTox3 Suppresses Oxidative Burst through the Ethylene Signaling Pathway by Regulating the Work of NADPH Oxidase and Provides the Growth of the Pathogen

Components of the host plant redox metabolism were studied at the initial stage of infection with S. nodorum in order to determine the role of NE SnTox3 and the contribution of the ethylene signaling pathway to the suppression of oxidative burst.

In our work, two peaks of $\mathrm{H}_{2} \mathrm{O}_{2}$ generation were found in SnTox3-insensitive plants Om35 infected with the isolate $\mathrm{SnB}$ at 6 and 24 hpi (Figure 3B). In the SnTox3-sensitive Kaz10 cultivar, no significant increase in the content of $\mathrm{H}_{2} \mathrm{O}_{2}$ was detected at the initial stage of infection (Figure 3A). Ethephon application suppressed the accumulation of $\mathrm{H}_{2} \mathrm{O}_{2}$ in both SnTox3-sensitive and SnTox3-insensitive plants at 6 and 24 hpi (Figure 3A,B). However, in the SnTox3-sensitive Kaz10 plants, the decrease in $\mathrm{H}_{2} \mathrm{O}_{2}$ content was more pronounced (Figure 3A). Conversely, exogenous 1-MCP application induced accumulation of $\mathrm{H}_{2} \mathrm{O}_{2}$ in leaves at 6 and 24 hpi in both Kaz10 and Om35 cultivars (Figure 3A,B). These results suggest that the change in the $\mathrm{H}_{2} \mathrm{O}_{2}$ content in infected wheat plants in our experiments completely depended on the activation or inhibition of the ethylene signaling pathway induced by SnTox3.

We have studied the transcription of TaRbohD and TaRbohF genes required for ROS accumulation in the plant defense response against pathogen infection $[43,44]$. The transcript levels of the TaRbohD gene at $6 \mathrm{hpi}$ and of the TaRbohF gene at $24 \mathrm{hpi}$ increased up to 4- and 5-fold in SnTox3-insensitive Om35 plants and plants treated with 1-MCP and infected with $\mathrm{SnB}$ (Figure 3C,D). This coincided with the peaks of $\mathrm{H}_{2} \mathrm{O}_{2}$ generation (Figure 3B). Moreover, the transcript level of the TaRbohD gene decreased at $24 \mathrm{hpi}$ in these plants, although it remained higher than in the control (Figure 3C). The opposite nature of the transcription of TaRbohD and TaRbohF genes was found in SnTox3-sensitive Kaz10- and ET-treated plants (Figure 3C,D). The slight increase in mRNA content of the TaRbohD gene was observed after $6 \mathrm{~h}$ of infection, followed by a significant increase up to 4- and 5-fold at $24 \mathrm{hpi}$ (Figure 3C). The transcript level of the TaRbohF gene did not change at 6 hpi and significantly decreased at 24 hpi compared to the control (Figure 3D). Importantly, treatment with 1-MCP of SnTox3-sensitive plants only partially restored the transcript level of the TaRbohF gene compared to SnTox3-insensitive plants infected with SnB (Figure 3D). Treatment with ET of SnTox3-insensitive plants only partially inhibited the transcript level of TaRbohF gene compared to SnTox3-sensitive plants infected with SnB (Figure 3D). Thus, our results suggest that SnTox3 downregulated TaRbohF and upregulated TaRbohD at 24 hpi. SnTox3 regulated TaRbohF transcription in ethylene-dependent and ethylene-independent manners.

Inoculation of both Kaz10 and Om35 cultivars with the avirulent isolate Sn4VD led to a slight two-fold increase in the transcript level of TaRbohD at $6 \mathrm{hpi}$, regardless of the treatment with either ET or 1-MCP, while the abundance of TaRbohD mRNA decreased at $24 \mathrm{hpi}$ in all variants except those treated with ET (Figure 3F). The transcript level of the TaRbohF gene increased up to 1.5-fold at $24 \mathrm{~h}$ after Sn4VD inoculation in all interaction variants (Figure 3E). These results suggest that the ethylene signaling pathway is capable of completely regulating $T a R b o h D$ gene transcription, but only partially regulating transcription of the TaRbohF gene. 
(A)

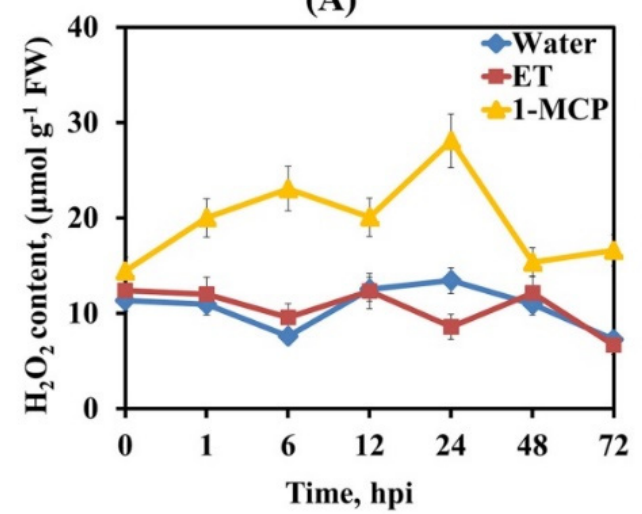

(C)

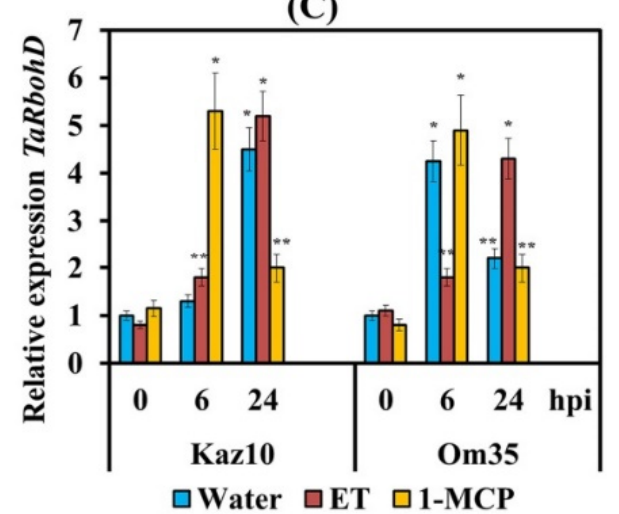

(E)

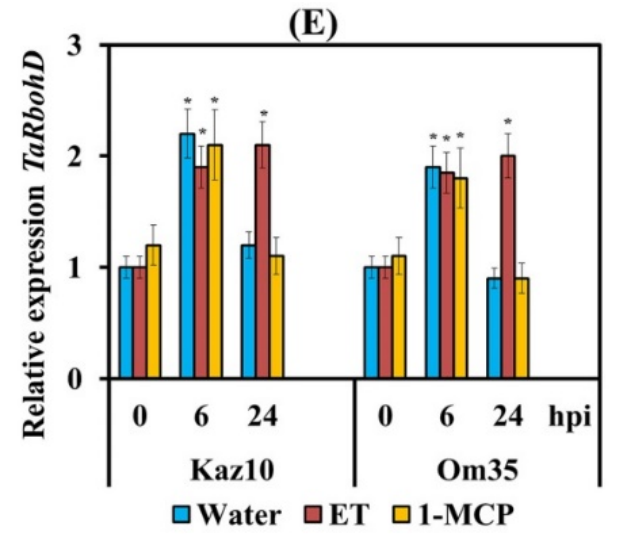

(B)



(D)



(F)

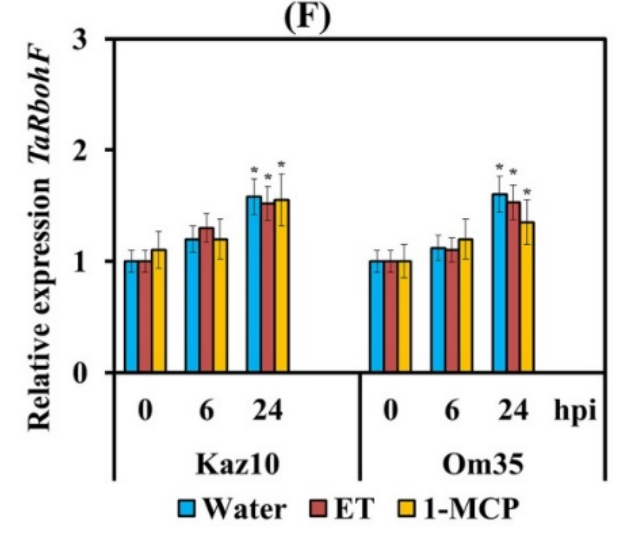

Figure 3. The effect of pretreatment with ethephone (ET) and 1-MCP on the $\mathrm{H}_{2} \mathrm{O}_{2}$ production and relative expression of genes encoding isozymes of NADPH oxidase in Kaz10 and Om35 wheat cultivars infected with virulent $\mathrm{SnB}$ and avirulent $\mathrm{Sn} 4 \mathrm{VD}$ S. nodorum isolates. (A) $\mathrm{H}_{2} \mathrm{O}_{2}$ production in Kaz10 infected with $\mathrm{SnB}$ in the dynamics of the infectious process. (B) $\mathrm{H}_{2} \mathrm{O}_{2}$ production in the Om35 infected with SnB in the dynamics of the infectious process. (C) The mRNA abundance of the TaRbohD in Kaz10 and Om35 infected with SnB. (D) The mRNA abundance of the TaRbohF gene in Kaz10 and Om35 infected with SnB. (E) The mRNA abundance of the TaRbohD gene in the Kaz10 and Om35 infected with Sn4VD. (F) The mRNA abundance of the TaRbohF gene in the Kaz10 and Om35 infected with Sn4VD. Expression values were normalized to the housekeeping gene TaRLI as an internal reference and expressed relative to the normalized expression levels in mock-treated control (Water) plants at 0 hpi. Symbols are the same as in Figure 2. Figures present means $\pm \mathrm{SE}$ $(n=6)$. Asterisks indicate means statistically different from the control and different number of asterisks $(*, * * * * *)$ allows distinguishing of significantly different variants according to the LSD test at ${ }^{*} p<0.05,{ }^{* *} p<0.01, * * * p<0.001$. 


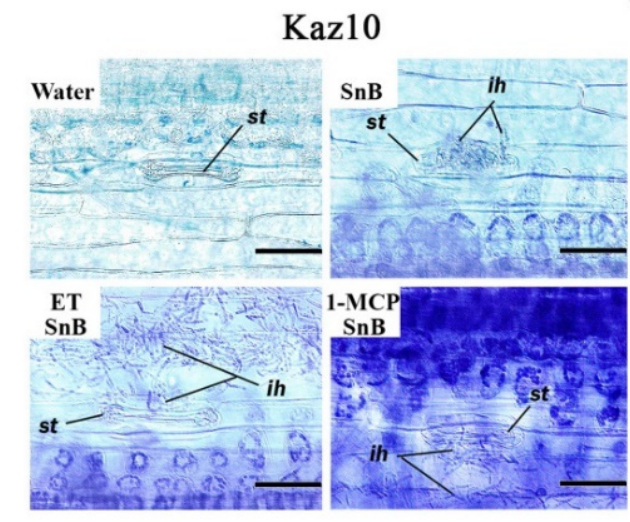

(A)
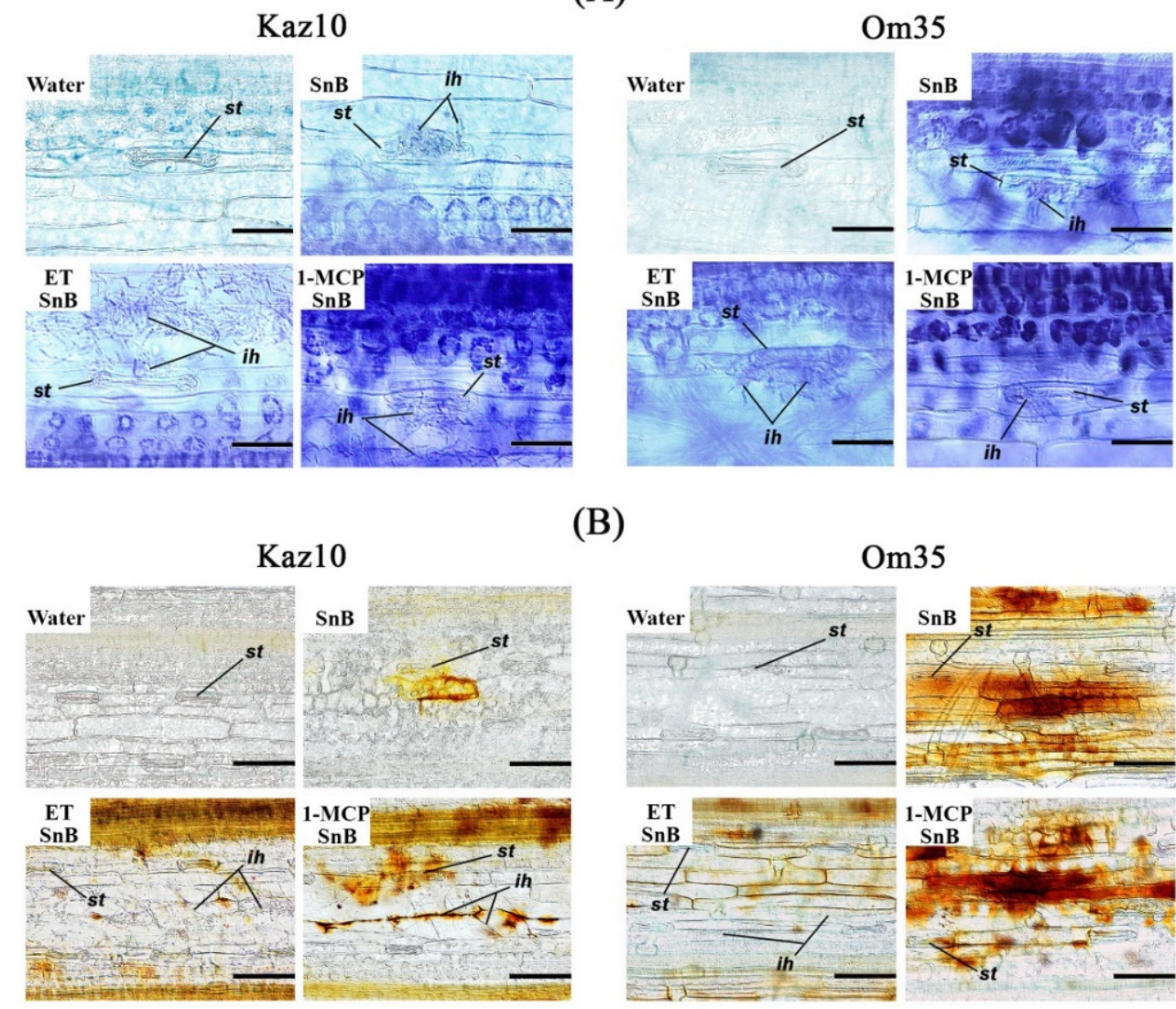

(B)

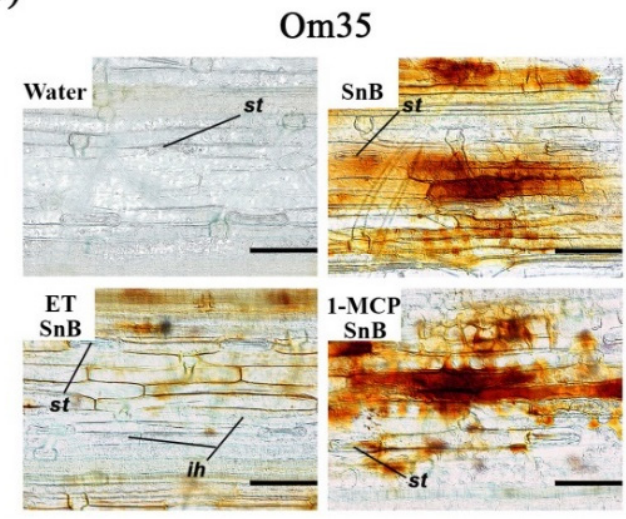

(C)

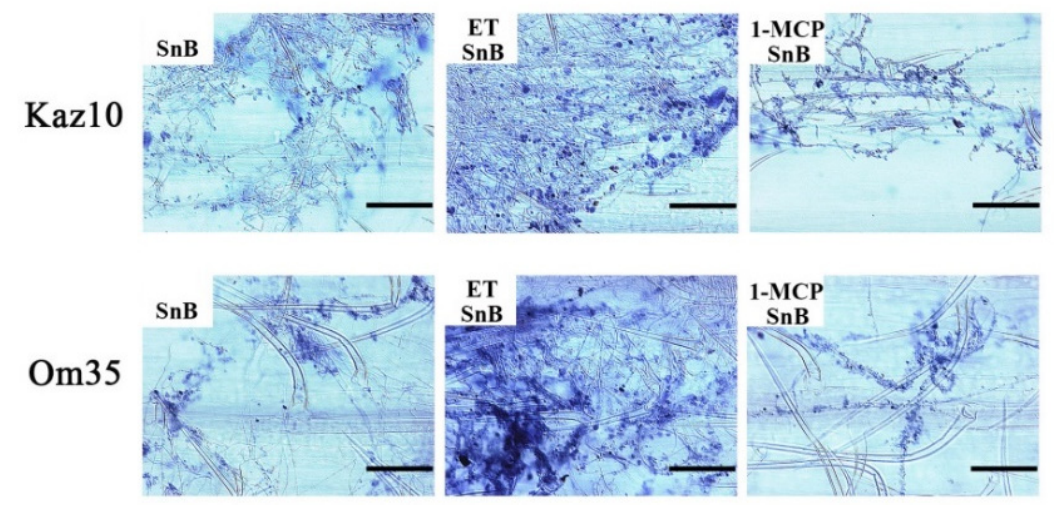

Figure 4. The effect of pretreatment with ethephone (ET) and 1-MCP on local generation of superoxide radical and $\mathrm{H}_{2} \mathrm{O}_{2}$ and growth of pathogen mycelium in leaves of Kaz10 and Om35 wheat cultivars infected with SnB. (A) Superoxide radical accumulation in infected leaves of Kaz10 and Om35 at 6 hpi detected with HBT staining. $\mathrm{Bar}=50 \mu \mathrm{m}$. (B) $\mathrm{H}_{2} \mathrm{O}_{2}$ accumulation in infected leaves of Kaz10 and Om35 at 24 hpi detected with diaminobenzidine (DAB) staining. Bar $=100 \mu \mathrm{m}$. (C) The development of the S. nodorum mycelium on the leaves of Kaz10 and Om35 at 24 hpi detected with aniline blue staining. Bar $=50 \mu \mathrm{m}$. The variants are numbered as follows: water-noninfected plants; SnBplants infected with the S. nodorum SnB; ETSnB-plants infected with S. nodorum SnB, treated with ethephone (ET); 1-MCPSnB-plants infected with S. nodorum SnB, treated with 1-methylcyclopropene (1-MCP). Photographs represent results of a typical variant from a series of experiments $(\mathrm{n}=10)$. ih-infections hyphae; st-stomata.

Then, we analyzed local accumulation of superoxide radicals and $\mathrm{H}_{2} \mathrm{O}_{2}$ at the site of pathogen invasion, as well as the proliferation of fungal mycelium with histochemical 
staining methods to gain clearer insight into the cellular defense reactions of wheat against S. nodorum (Figure 4). Spore germination and penetration of fungal hyphae through the stomata occurred within 6 hpi (Figure 4A). Staining with NBT revealed a very strong accumulation of superoxide radical in hyphae-containing epidermis and mesophyll cells under stomata $6 \mathrm{~h}$ after infection with the isolate SnB of SnTox3-insensitive Om35 plants and plants treated with 1-MCP (Figure 4A). In this case, the mycelium is poorly developed on the plants leaves (Figure 4C).

Staining with DAB of SnTox3-insensitive Om35 plants and plants treated with 1-MCP revealed a very strong accumulation of $\mathrm{H}_{2} \mathrm{O}_{2}$ in epidermis and mesophyll cells at the sites of pathogen penetration at $24 \mathrm{hpi}$ (Figure $4 \mathrm{~B}$ ). In this case, $\mathrm{H}_{2} \mathrm{O}_{2}$ performed a direct biocidal function. On the contrary, a small accumulation of superoxide radical in hyphaecontaining mesophyll cells under stomata was observed in SnTox3-sensitive Kaz10 plants and ET-treated plants at $6 \mathrm{hpi}$ (Figure 4A). This resulted in the rapid propagation of the pathogen mycelium on the leaf surface and the appearance of numerous sites of penetration into the plant at $24 \mathrm{hpi}$ (Figure 4C). Intensive mycelium growth was accompanied by almost complete absence of $\mathrm{H}_{2} \mathrm{O}_{2}$ accumulation in stomata, epidermis and mesophyll cells in the places of fungus penetration at $24 \mathrm{hpi}$ (Figure 4B). These observations suggest that restriction of fungal proliferation occurred mainly at the stage of infection spread in the mesophyll due to the intense local accumulation of the superoxide radicals and $\mathrm{H}_{2} \mathrm{O}_{2}$. Conversely, the ethylene signaling pathway induced by SnTox 3 created favorable conditions for the penetration and propagation of S. nodorum in wheat leaf tissues by suppressing the oxidative burst at the initial stage of infection.

\subsection{Cytokinins Enhance the Oxidative Burst, Limit the Growth of the Pathogen and Trigger the Salicylate Signaling Pathway}

An important function of CKs, both in the processes of growth and development, and under the influence of stress factors, is the regulation of plant redox metabolism [45]. One of the most important effects of CKs is a delay in senescence, and they also have an antioxidant effect on plants [46]. Interestingly, at high concentrations, CKs induce growth inhibition, control programmed cell death (PCD) in the development and senescence program [45], and also increase the production of ROS during plant responses to stress factors of various natures [38,47].

Before inoculation with the virulent isolate of SnB, the SnTox3-insensitive Om35 and SnTox3-sensitive Kaz10 were treated with either trans-zeatin $(2.5 \mu \mathrm{M})$ or salicylic acid (SA) $(50 \mu \mathrm{M})$ to study the role of CKs and SA in the development of wheat defense responses against S. nodorum. Treatment with trans-zeatin or SA reduced the virulence of SnB in both Om35 and Kaz10 cultivars. Leaves of both cultivars treated with trans-zeatin developed small lesion zones, which consisted only of necrosis and occupied about $9 \%$ of the total leaf area (Figure 5A,B). The response of both cultivars to SA treatment was similar to the response upon trans-zeatin treatment; however, necrosis spots were smaller in area and additionally small chloroses were observed on the leaves of both cultivars (Figure 5A,B). These data uncover the role of CKss and SA as activators of induced resistance against S. nodorum.

Treatment with either trans-zeatin or SA induced two peaks of $\mathrm{H}_{2} \mathrm{O}_{2}$ generation 6 and $24 \mathrm{~h}$ after infection with the isolate $\mathrm{SnB}$ of SnTox3-sensitive Kaz10 cultivar and increased $\mathrm{H}_{2} \mathrm{O}_{2}$ production in the SnTox3-insensitive Om35 cultivar (Figure $5 \mathrm{C}$ ). The pattern of changes in the transcript levels of TaRbohD and TaRbohF genes upon inoculation with the $\mathrm{SnB}$ of plants of both cultivars treated with either trans-zeatin or SA was the same as in SnTox3-insensitive cultivar Om35 (Figure 6A,B). The transcript level of the TaRbohD gene was strongly accumulated at $6 \mathrm{hpi}$, and the mRNA content of the TaRbohF gene significantly increased at $24 \mathrm{hpi}$, which coincided with the peaks of $\mathrm{H}_{2} \mathrm{O}_{2}$ generation (Figure 5C). In addition, the oxidative burst in both cultivars treated with either transzeatin or SA and infected with SnB was accompanied by a significant increase in the activity of free peroxidases and inhibition of catalase activity, similar to the response of the SnTox3-insensitive Om35 cultivar (Figure 6C,D). In contrast, the compatibility reaction in 
the SnTox3-sensitive Kaz10 cultivar was characterized by a slight increase in peroxidase activity and a strong increase in catalase activity at an early stage of infection, which could lead to the absence of oxidative burst found in SnTox3-sensitive Kaz10 cultivar (Figure 6C,D). Our results show that cytokinins and SA trigger defense reactions in wheat against $S$. nodorum due to the induction of oxidative burst at an early stage of infection by acting on the enzymes of redox metabolism, such as NADPH oxidase, peroxidase, and catalase.

(A)



(B)

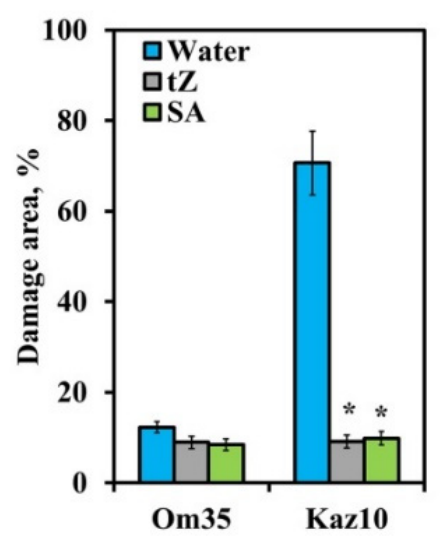

(C)
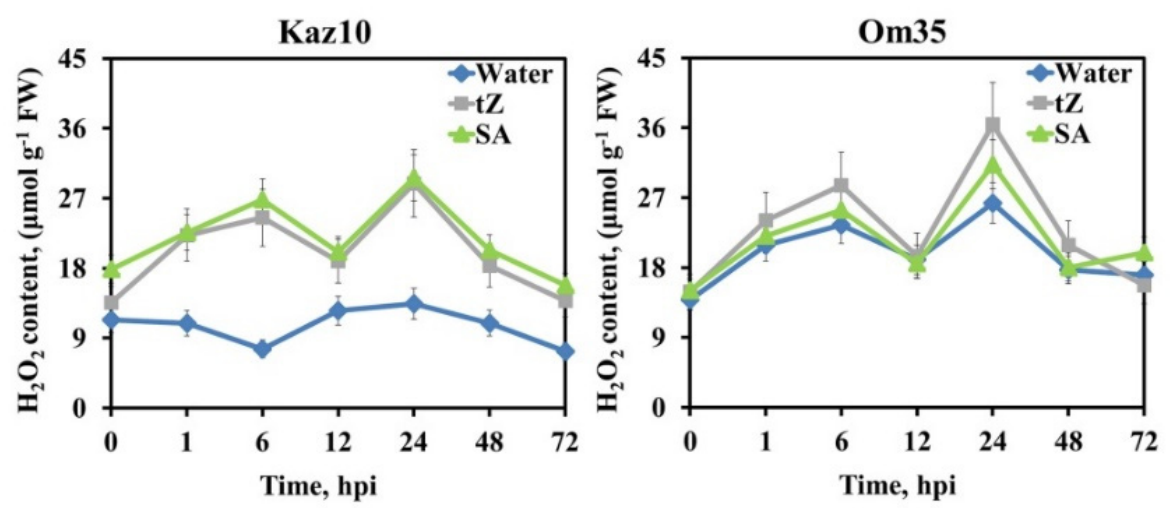

Figure 5. The pretreatment of trans-zeatin (tZ) and Salicylic acid (SA) induced an oxidative burst and reduced the damage zones on the leaves Kaz10 and Om35 cultivars infected with SnB. (A) Septoria nodorum blotch symptoms 8 days after inoculation. Photographs represent results of a typical variant from a series of experiments. (B) Damage zones on the leaves of Kaz10 and Om35 on the eighth day of inoculation, expressed as percentage of the total leaf area. Figures present means $\pm S E(n=30)$. (C) $\mathrm{H}_{2} \mathrm{O}_{2}$ production in Kaz10 and Om35 infected with $\mathrm{SnB}$ in the dynamics of the infectious process. Figures present means \pm SE $(n=6)$. The variants are indicated as follows: water-noninfected plants (0 hpi) or plants infected with the $S$. nodorum, which have been sprayed with water; $\mathrm{Z} Z$-noninfected plants ( 0 hpi) or plants infected with $S$. nodorum, treated with trans-zeatin; SA- uninfected plants (0 hpi) or plants infected with S. nodorum, treated with salicylic acid. Asterisks indicate means statistically different from the control group infected with $S$. nodorum without any pretreatments according to the LSD test at $p<0.05$. 
(A)

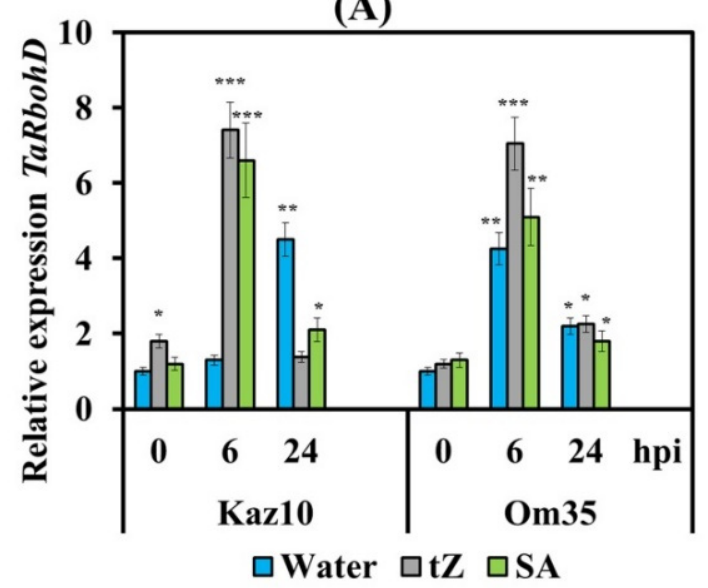

(C)

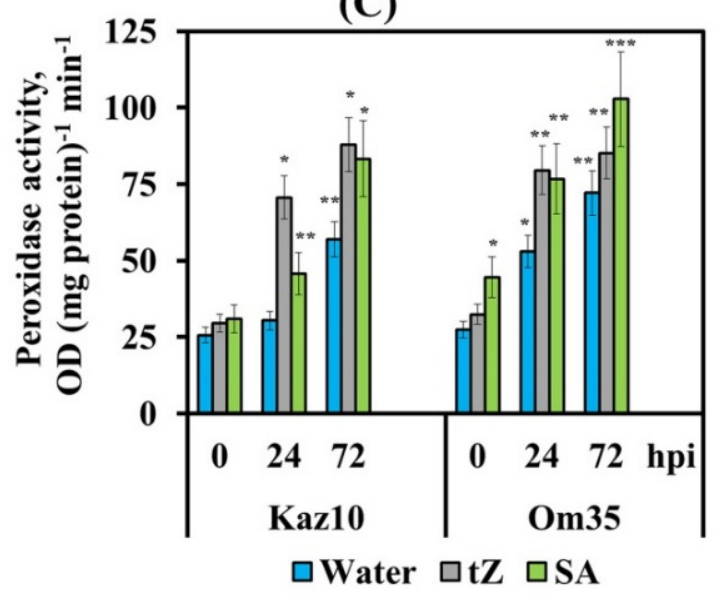

(B)

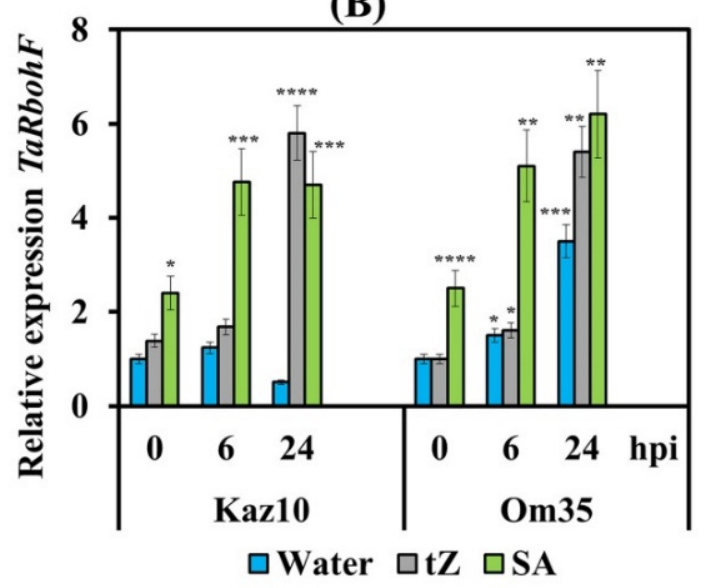

(D)



Figure 6. The effect of pretreatment with $\mathrm{tZ}$ and SA on the relative expression of genes encoding NADPH oxidase, and activity of peroxidase and catalase in two wheat cultivars of in Kaz10 and Om35 infected with SnB. (A) The mRNA abundance of the TaRbohD gene in the Kaz10 and Om35 at 6 and 24 hpi. (B) The mRNA abundance of the TaRbohF gene in the two Kaz10 and Om35 cultivars at 6 and 24 hpi. Expression values were normalized to the housekeeping gene TaRLI as an internal reference and expressed relative to the normalized expression levels in mock-treated control (water) plants at 0 hpi. (C) Peroxidase activity in the Kaz10 and Om35 cultivars at 24 and 72 hpi. (D) Catalase activity in the Kaz10 and Om35 cultivars at 24 and $72 \mathrm{hpi}$. Symbols are the same as in Figure 5. Figures present means \pm SE $(n=6)$. Asterisks indicate means statistically different from the control and different number of asterisks $(*, * *, * * *, * * *)$ allows distinguishing of significantly different variants according to the LSD test at $p<0.05,{ }^{* *} p<0.01,{ }^{* * *} p<0.001,{ }^{* * * *} p<0.0001$.

To understand whether cytokinins induce SA-dependent defense reactions, we examined the transcription of salicylate signaling pathway marker genes $P R-1$ and $P R-2$ in Om35 and Kaz10 varieties after their treatment with either trans-zeatin or SA and infection with virulent isolate SnB. The transcript levels of $P R-1$ and $P R-2$ genes did not increase in the SnTox3sensitive cultivar Kaz10 at 24 hpi (Figure 7). The mRNA abundance of $P R-1$ and $P R-2$ genes increased up to 3-fold in the SnTox3-insensitive cultivar Om35 at 24 hpi (Figure 7). These results clearly indicate that resistance in SnTox3-insensitive cultivar developed in an SA-dependent manner. Treatment with either trans-zeatin or SA significantly increased mRNA accumulation of $P R-1$ and $P R-2$ genes in both SnTox3-sensitive and SnTox3-insensitive cultivars at $24 \mathrm{hpi}$ (Figure 7). Our data suggest that cytokinins induce SA-dependent resistance mechanisms in wheat against $S$. nodorum associated with the development of oxidative burst at the early stages of infection. 
(A)

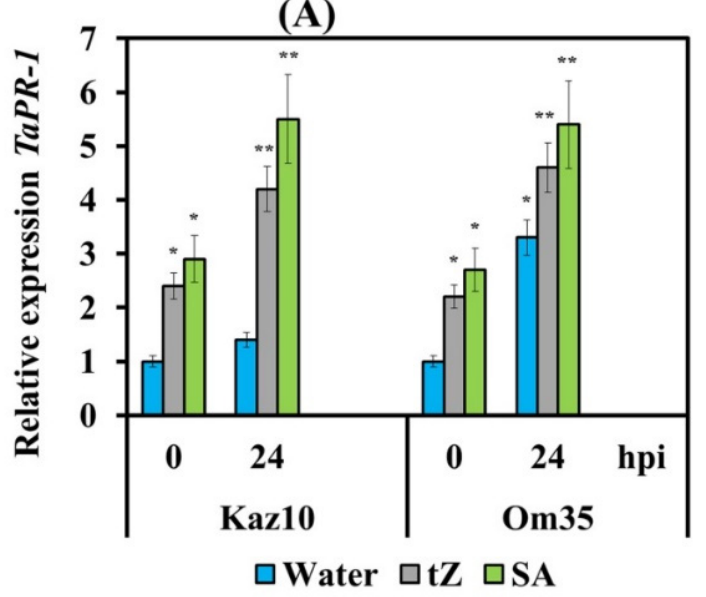

(B)

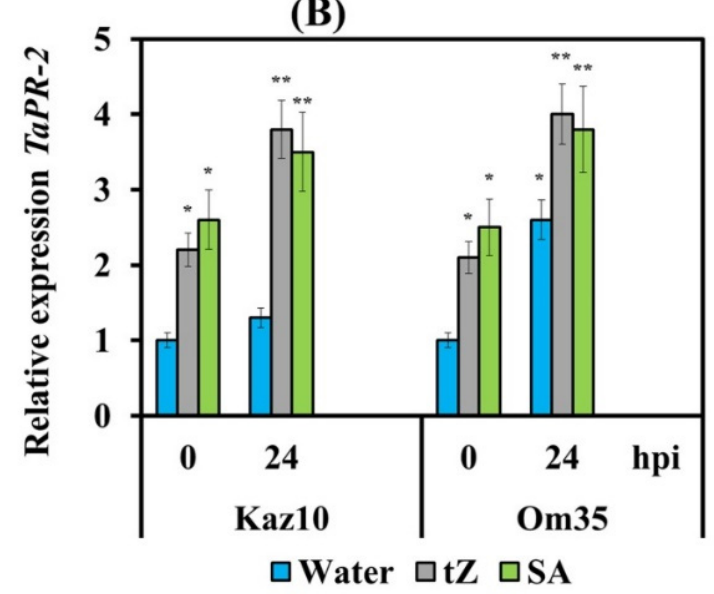

Figure 7. The effect of pretreatment with $\mathrm{tZ}$ and $\mathrm{SA}$ on the relative expression of salicylate signaling pathway marker genes TaPR-1 and TAPR-2 in Om35 and Kaz10 infected with SnB. (A) The mRNA abundance of the TaPR-1 gene. (B) TaPR-2 gene. Expression values are normalized to the housekeeping gene TaRLI as an internal reference and expressed relative to the normalized expression levels in mock-treated control (water) plants at 0 hpi. Symbols are the same as in Figure 5 . Figures present means $\pm S E(n=6)$. Asterisks indicate means statistically different from the control and different number of asterisks $\left({ }^{*}, * *\right)$ allows distinguishing of significantly different variants according to the LSD test at ${ }^{*} p<0.05,{ }^{* *} p<0.01$.

3.4. SnTox3 and Ethylene Regulate Biosynthesis and Metabolism of Cytokinins During Defense Response of Wheat against $S$. nodorum

We have previously shown that enhanced resistance of wheat plants against $S$. nodorum was accompanied by an increase in zeatin content in the leaves. Ethephon treatment reduced zeatin content in infected leaves and, conversely, treatment with 1-MCP increased the content of this phytohormone [28]. In this work, we determined the changes in the content of the most biologically active forms of CKs: N6-( $\Delta 2$-isopentenyl)-adenine, (iP) $\mathrm{N}^{6}-\left(\Delta^{2}\right.$-isopentenyl)-adenosine (iPR), zeatin (Z), and zeatin riboside (ZR) in both Kaz10 and Om35 cultivars, treated with either ET or 1-MCP and inoculated with either SnB or Sn4VD. In addition, reversible storage forms of cytokinins (Z-O-glucoside (Z-OG)) and inactive forms (zeatin-9-N-glucoside (Z-9G)) were also measured. In addition, to clarify the mechanism underlying regulation of the active form levels of CKs in wheat infected with $S$. nodorum, we analyzed gene transcription of individual members of the IPT, CKX, ZOG, and GLU multigene families involved in CK biosynthesis and metabolism. TaIPT gene family members encode adenosine phosphate-isopentenyltransferase isoforms that catalyze the synthesis of cytokinins by attaching an isopentenyl radical to the purine ring of adenine; TaZOG gene family members encode isoforms of zeatin-O-glucosyl transferases that catalyze the reaction of O-glucosylation (inactivating cytokinins by their conjugation with glucose radical); TaGLU gene family members encode $\beta$-glucosidase isoforms that catalyze the deglucosylation reaction (the conversion of the bound form of O-glucosides into the active form); TaCKX gene family members encode isoforms of cytokinin oxidases that catalyze oxidative degradation of CK $[48,49]$.

In incompatible interactions (Om35/SnB, Om35/Sn4VD, Kaz10/Sn4VD), we observed an increase in the content of all active forms of $\mathrm{CK}-\mathrm{Z}, \mathrm{iP}$ and their ribozides at $24 \mathrm{hpi}$ (Table 1). Amount of CK active forms increased up to 2-fold (Table 1). Along with this, a very high mRNA accumulation of TaIPT2 and TaIPT5 genes was observed in incompatible interactions as early as $6 \mathrm{~h}$ after infection (Figure 8A,B). In the compatible interaction (Kaz10/SnB), we observed no increase in concentrations of CK active forms at 24 hpi (Table 1). The levels of $\mathrm{Z}$ and iPR decreased by 1.5 and 2 times, respectively, compared with uninfected control (Table 1), and a 2-fold decline in the transcript levels of the TaIPT2 and TaIPT5 genes was also found in a compatible interaction (Figure 8A,B). These results clearly indicate that the pathogen $S$. nodorum can induce a decrease in CK active forms by inhibiting CK biosynthesis. 

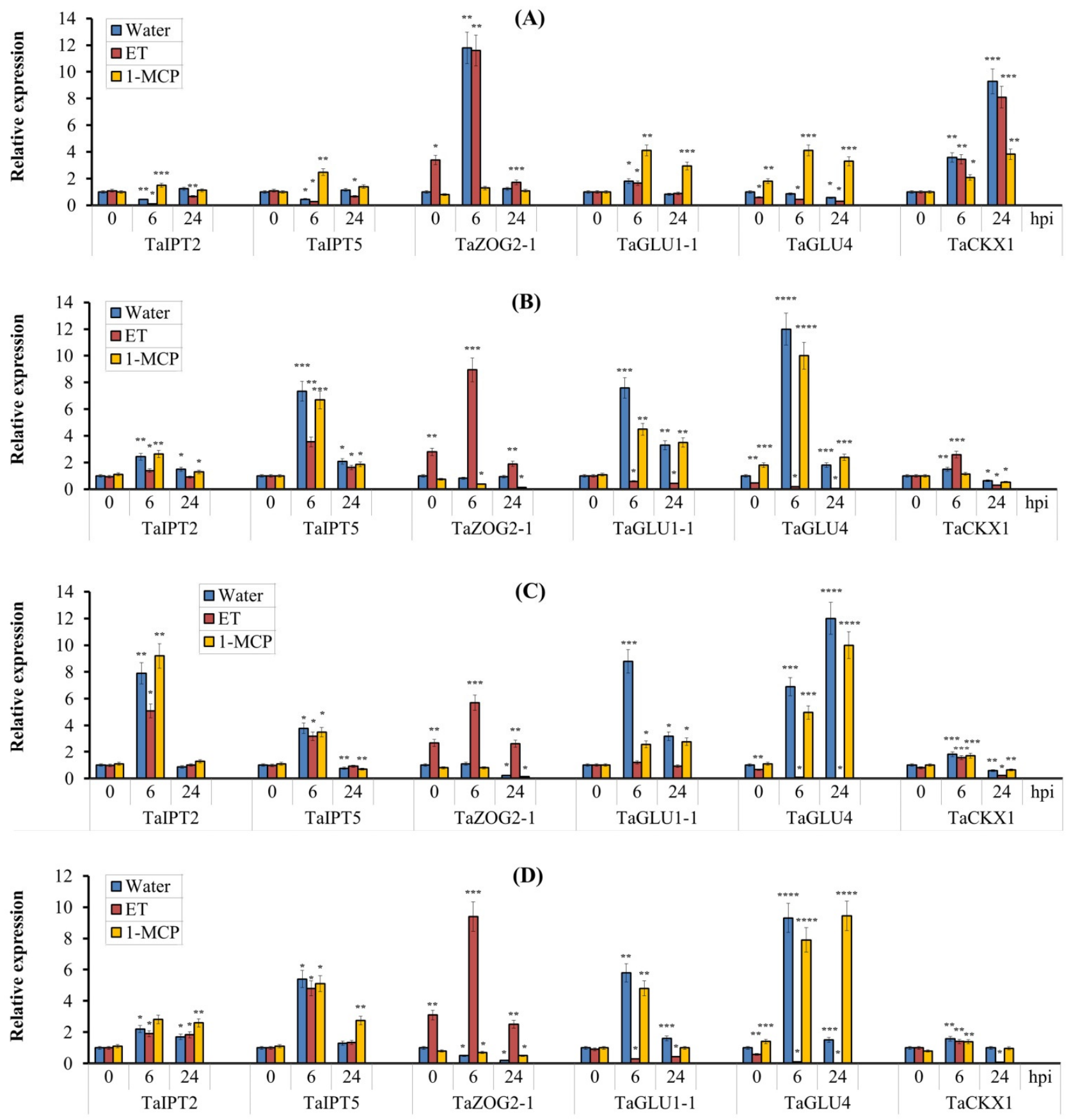

Figure 8. The effect of pretreatment with ethephone (ET) and 1-MCP on the relative expression of genes involved in the biosynthesis (TaIPT2, TaIPT5), O-glucosylation (TaZOG2-1), deglucosylation (TaGLU1-1, TaGLU4), and oxidative degradation (TaCKX1) of cytokinins in two wheat cultivars of Kaz10 (A,C) and Om35 (B,D) infected with virulent SnB (A,B) and avirulent Sn4VD S. nodorum isolates (C,D). Expression values were normalized to the housekeeping gene TaRLI as an internal reference and expressed relative to the normalized expression levels in mock-treated control (water) plants at 0 hpi. Symbols are the same as in Figure 2. Figures present means \pm SE $(n=6)$. Asterisks indicate means statistically different from the control and different number of asterisks allows $(*, * *, * * *, * * * *)$ distinguishing of significantly different variants according to the LSD test at ${ }^{*} p<0.05,{ }^{* *} p<0.01,{ }^{* * *} p<0.001,{ }^{* * * *} p<0.0001$.

Decrease in CK active forms similar to the compatible interaction of Kaz10/SnB was found in ET-treated SnTox3-sensitive Kaz10 plants infected with virulent SnB (Kaz10/SnB/ET) (Table 1). Furthermore, these plants showed a stronger suppression of transcription of TaIPT2 and TaIPT5 genes compared to Kaz10/SnB (Figure 8A,B). Importantly, in the case of the compatible interaction of Kaz10/SnB, pretreatment with 1-MCP only partially restored the 
accumulation of CK active forms (especially $\mathrm{Z}$ and iPR) (Table 1 ) and the transcript levels of the TaIPT2, TaIPT5 genes, compared with the incompatible interaction Om35/SnB (Figure 8A,B). These results suggest that inhibition of CK biosynthesis involves both ethylene-dependent and -independent signaling pathways. Treatment with ET of SnTox3-insensitive Om35 plants infected with virulent $\mathrm{SnB}(\mathrm{Om} 35 / \mathrm{SnB} / \mathrm{ET})$ prevented accumulation of $\mathrm{CK}$ active forms and partially inhibited transcription of the TaIPT2 and TaIPT5 genes compared to the incompatible interaction Om35/SnB (Table 1, Figure 8A,B). Importantly, the 1-MCP pretreatment of such plants completely restored the increased levels of $\mathrm{CK}$ active forms and transcript levels of TaIPT2 and TaIPT5 genes to the values characteristic of incompatible interaction of Om35/SnB (Table 1, Figure $8 \mathrm{~A}, \mathrm{~B}$ ). This proves only partial involvement of the ethylene signaling pathway in this process. Treatment with ET as well as 1-MCP of SnTox3-sensitive Kaz10 and SnTox3insensitive Om35 plants infected with avirulent Sn4VD did not affect the accumulation of mRNA of TaIPT2 and TaIPT5 genes and insignificantly affected the level of CK active forms (Table 2, Figure 8C,D).

Table 1. The effects of pretreatment with ethephone (ET) and 1-MCP on the content of cytokinins (pmol/g FW) in leaves of two Omskaya 35 and Kazakhstanskaya 10 cultivars at $24 \mathrm{~h}$ after inoculation with virulent S. nodorum isolate SnB.

\begin{tabular}{|c|c|c|c|c|c|c|c|c|}
\hline \multirow[b]{2}{*}{ Variety } & \multirow[b]{2}{*}{ Treatments } & \multicolumn{7}{|c|}{ The Most Biologically Active Forms and Inactive Forms of CKs } \\
\hline & & $\mathbf{Z}$ & ZR & iP & iPR & Z-9G & Z-OG & $\begin{array}{c}\text { Amount of CK } \\
\text { Active Forms } \\
(Z, Z R, i P, i P R)\end{array}$ \\
\hline \multirow{6}{*}{ Kaz10 } & Water & $40.5 \pm 3.2$ & $11.7 \pm 0.9$ & $5.1 \pm 0.4$ & $24.9 \pm 1.9$ & $40.9 \pm 3.2$ & $11.4 \pm 0.9$ & $82.2 \pm 6.5$ \\
\hline & $\mathrm{SnB}$ & $30.3 \pm 2.4 *$ & $11.2 \pm 0.9$ & $14.1 \pm 1.1$ * & $12.4 \pm 0.9 *$ & $63.1 \pm 5.0 *$ & $23.3 \pm 1.8$ * & $67.8 \pm 5.4 *$ \\
\hline & ET & $36.5 \pm 2.9$ & $15.7 \pm 1.3$ & $8.3 \pm 0.7$ & $18.5 \pm 1.4$ & $63.1 \pm 5.0 *$ & $39.9 \pm 3.1^{* *}$ & $78.8 \pm 6.3 *$ \\
\hline & $\mathrm{ET}+\mathrm{SnB}$ & $32.3 \pm 2.6^{*}$ & $16.1 \pm 1.3$ & $17.1 \pm 1.4^{*}$ & $14.2 \pm 1.1^{*}$ & $68.4 \pm 5.4^{*}$ & $36.2 \pm 2.9 * *$ & $79.7 \pm 6.3 *$ \\
\hline & 1-MCP & $38.9 \pm 3.1$ & $14.1 \pm 1.1$ & $7.1 \pm 0.5$ & $21.3 \pm 1.7$ & $39.7 \pm 3.1^{* *}$ & $8.9 \pm 0.7$ & $81.5 \pm 6.5$ \\
\hline & $1-\mathrm{MCP}+\mathrm{SnB}$ & $60.6 \pm 4.8^{* *}$ & $32.9 \pm 2.6 *$ & $33.6 \pm 2.6^{* *}$ & $36.9 \pm 2.9 * *$ & $34.1 \pm 2.7^{* *}$ & $6.6 \pm 0.5^{* * *}$ & $164.0 \pm 13.1^{* *}$ \\
\hline \multirow{6}{*}{ Om35 } & Water & $28.9 \pm 2.3$ & $13.7 \pm 1.1$ & $8.2 \pm 0.6$ & $22.4 \pm 1.7$ & $54.7 \pm 4.3$ & $3.7 \pm 0.2$ & $73.3 \pm 5.8$ \\
\hline & $\mathrm{SnB}$ & $82.6 \pm 6.1 *$ & $38.6 \pm 3.0 *$ & $37.7 \pm 3.0 *$ & $49.8 \pm 3.9 *$ & $43.8 \pm 3.5 *$ & $0.8 \pm 0.6 *$ & $208.8 \pm 16.7 *$ \\
\hline & ET & $36.4 \pm 2.9 * *$ & $13.1 \pm 1.0$ & $9.2 \pm 0.7$ & $23.0 \pm 1.8$ & $55.5 \pm 4.4$ & $13.5 \pm 1.0 * *$ & $81.8 \pm 6.5^{* *}$ \\
\hline & $\mathrm{ET}+\mathrm{SnB}$ & $30.4 \pm 2.4$ & $17.1 \pm 1.3$ & $33.6 \pm 2.6 *$ & $34.8 \pm 2.7^{* *}$ & $66.8 \pm 5.3 * *$ & $45.1 \pm 3.6^{* * *}$ & $116.0 \pm 9.2^{* * *}$ \\
\hline & 1-MCP & $33.1 \pm 2.6$ & $13.4 \pm 1.0$ & $10.9 \pm 0.8$ & $28.4 \pm 2.2$ & $39.2 \pm 3.1 *$ & $9.9 \pm 0.7^{* *}$ & $85.9 \pm 6.8^{* *}$ \\
\hline & $1-\mathrm{MCP}+\mathrm{SnB}$ & $85.8 \pm 6.9^{*}$ & $40.4 \pm 3.2 *$ & $31.9 \pm 2.5^{*}$ & $56.8 \pm 4.5^{*}$ & $26.2 \pm 2.0^{* * *}$ & $0.9 \pm 0.1^{*}$ & $215.0 \pm 17.2 *$ \\
\hline
\end{tabular}

Asterisks indicate means statistically different from the control in each cultivar and different number of asterisks $\left({ }^{*},{ }^{* *},{ }^{* * *}\right)$ allows distinguishing of significantly different variants according to the LSD test $\left(\mathrm{n}=6,{ }^{*} p<0.05,{ }^{* *} p<0.01,{ }^{* * *} p<0.001\right)$.

Table 2. The effect of pretreatment with ethephone (ET) and 1-MCP on the content of cytokinins (pmol/g FW) in leaves of Omskaya 35 and Kazakhstanskaya cultivars 10 at $24 \mathrm{~h}$ after inoculation with S. nodorum avirulent isolate Sn4VD.

\begin{tabular}{|c|c|c|c|c|c|c|c|c|}
\hline \multirow[b]{2}{*}{ Variety } & \multirow[b]{2}{*}{ Treatments } & \multicolumn{7}{|c|}{ The Most Biologically Active Forms and Inactive Forms of CKs } \\
\hline & & $\mathbf{Z}$ & ZR & iP & iPR & Z-9G & Z-OG & $\begin{array}{c}\text { Amount of CK } \\
\text { Active Forms } \\
(Z, Z R, i P, i P R)\end{array}$ \\
\hline \multirow{6}{*}{ Kaz10 } & Water & $39.8 \pm 3.1$ & $11.6 \pm 0.9$ & $4.9 \pm 0.4$ & $22.5 \pm 1.8$ & $34.8 \pm 2.7$ & $8.8 \pm 0.7$ & $79.0 \pm 6.3$ \\
\hline & Sn4VD & $70.3 \pm 5.6 *$ & $19.3 \pm 1.5 *$ & $27.3 \pm 2.1 *$ & $47.7 \pm 3.8 *$ & $42.3 \pm 3.3 *$ & $0.6 \pm 0.1 *$ & $164.8 \pm 13.1 *$ \\
\hline & ET & $49.5 \pm 3.9$ & $15.2 \pm 1.2$ & $8.6 \pm 0.6^{* *}$ & $16.7 \pm 1$ & $43.3 \pm 3.4 *$ & $16.7 \pm 1.3^{* *}$ & $90.2 \pm 7.2$ \\
\hline & $\mathrm{ET}+\mathrm{Sn} 4 \mathrm{VD}$ & $63.5 \pm 5.0 *$ & $18.1 \pm 1.4^{*}$ & $25.2 \pm 2.0 *$ & $34.6 \pm 2.7^{* *}$ & $47.3 \pm 3.7^{*}$ & $14.0 \pm 1.1^{* *}$ & $141.5 \pm 11.3^{*}$ \\
\hline & 1-MCP & $72.7 \pm 5.8 *$ & $11.7 \pm 0.9$ & $5.1 \pm 0.4$ & $26.0 \pm 2.0$ & $43.7 \pm 3.5 *$ & $1.0 \pm 0.1 *$ & $115.6 \pm 9.2^{* *}$ \\
\hline & $1-\mathrm{MCP}+\mathrm{Sn} 4 \mathrm{VD}$ & $90.0 \pm 7.2^{* *}$ & $17.6 \pm 1.4 *$ & $32.3 \pm 2.5 *$ & $52.2 \pm 4.1 *$ & $29.1 \pm 2.3^{* *}$ & $1.4 \pm 0.1 *$ & $192.2 \pm 15.3^{* * *}$ \\
\hline \multirow{6}{*}{ Om35 } & Water & $39.7 \pm 3.1$ & $11.9 \pm 0.9$ & $9.7 \pm 0.7$ & $20.9 \pm 1.6$ & $40.9 \pm 3.2$ & $7.6 \pm 0.6$ & $82.4 \pm 6.6$ \\
\hline & Sn4VD & $70.2 \pm 5.6^{*}$ & $24.5 \pm 1.9 *$ & $26.4 \pm 2.1 *$ & $41.5 \pm 3.3^{*}$ & $37.2 \pm 2.9$ & $1.0 \pm 0.1^{*}$ & $162.8 \pm 13.0 *$ \\
\hline & ET & $39.9 \pm 3.2$ & $14.8 \pm 1.1$ & $11.8 \pm 0.9$ & $20.6 \pm 1.6$ & $49.9 \pm 4.0$ & $17.7 \pm 1.4^{* *}$ & $87.3 \pm 6.9$ \\
\hline & $\mathrm{ET}+\mathrm{Sn} 4 \mathrm{VD}$ & $46.8 \pm 3.7^{* *}$ & $23.5 \pm 1.8 *$ & $30.6 \pm 2.4 *$ & $42.8 \pm 3.4^{*}$ & $41.5 \pm 3.3$ & $9.5 \pm 0.7$ & $143.7 \pm 11.5^{*}$ \\
\hline & 1-MCP & $35.0 \pm 2.8$ & $16.5 \pm 1.3$ & $8.0 \pm 0.6$ & $17.3 \pm 1.3$ & $40.7 \pm 3.2$ & $9.9 \pm 0.8$ & $76.9 \pm 6.1$ \\
\hline & 1-MCP + Sn4VD & $88.3 \pm 7.0^{* * *}$ & $28.0 \pm 3.7^{*}$ & $46.8 \pm 3.7^{* *}$ & $43.7 \pm 3.5^{*}$ & $37.7 \pm 3.0$ & $1.4 \pm 0.1 *$ & $207.0 \pm 16.5^{* *}$ \\
\hline
\end{tabular}

Asterisks indicate means statistically different from the control in each cultivar and different number of asterisks allows $(*, * *, * *)$ distinguishing of significantly different variants according to the LSD test $\left(\mathrm{n}=6,{ }^{*} p<0.05,{ }^{* *} p<0.01,{ }^{* * *} p<0.001\right)$. 
A slight decrease in the amount of CK active forms was found in ET-treated plants infected with Sn4VD, and a slight increase in the amount of CK active forms was found in 1-MCP-treated Sn4VD-infected plants, which was in both cases mainly due to changes in $\mathrm{Z}$ concentration (Table 2). Thus, suppression of CK biosynthesis was not found in plants infected with the avirulent Sn4VD nonexpressing SnTox3 gene.

CK metabolism plays an important role in the regulation of the levels of active CKs. Glucosylation is a major step in the metabolism of cytokinins [48]. In incompatible interactions (Om35/SnB, Om35/Sn4VD, Kaz10/Sn4VD), increases in the levels of active CK forms was accompanied by a decrease in Z-OG content, while Z-9G content did not change (Tables 1 and 2). This correlated with the increase in mRNA abundance of the TaGLU1-1 and TaGLU4 genes and a decrease in the transcript level of the TaZOG2-1 gene (Figure 8). It may suggest a release of CK active forms from bound Z-OG forms and a decrease in the activity of the glucosylation reaction. In a compatible interaction (Kaz10/SnB), s reduction in CK active forms levels was accompanied by significant increase in the Z-9G and Z-OG contents up to 1.5- and 2-fold, respectively (Table 1), which correlated with a very high (up to 12-fold) mRNA accumulation of the TaZOG2-1 gene and 2-fold downregulation of TaGLU4 gene compared to uninfected plants (Figure 8A,B). This may suggest a sharp induction of the glucosylation and a decline in deglucosylation.

Ethephone treatment without infection led to about to 2-3-fold accumulation of Z-9G and Z-OG compared to untreated plants (Tables 1 and 2). This was accompanied by about 3-fold upregulation of the TaZOG2-1 gene and a slight decline in mRNA abundance of the TaGLU4 gene (Figure 8A,B). Treatment with 1-MCP prevents the effects of ethylene. 1-MCP-treated noninfected Om35 and Kaz10 plants showed a reduction in Z-OG levels and a decrease in mRNA abundance of TaZOG2-1 gene (Table 1, Figure 8A,B). These results uncover the role of ethylene in the glucosylation reaction. During infection, treatment with ET also led to 2-3-fold increase in Z-9G and Z-OG (Tables 1 and 2), a very strong (from 6- to 12-fold) increase in transcript level of TaZOG2-1, a decline in mRNA abundance of the TaGLU1-1 gene, and an extreme (from 2- to 30-fold) decrease in transcripts of the TaGLU4 gene (Figure 8) in all variants (Om35/SnB/ET, Om35/Sn4VD/ET, Kaz10/SnB/ET, Kaz10/Sn4VD/ET), regardless of the genotype of either pathogen or host. This clearly indicates that ethylene has a role in this process. During infection, treatment with 1-MCP prevented the effect of ethylene. In the 1-MCP-treated SnTox3-sensitive Kaz10 and SnTox3-insensitive Om35 plants infected with either virulent $\mathrm{SnB}$ or avirulent Sn4VD, we observed reduced levels of Z-OG, no significant changes in Z-9G concentrations, increase in transcript levels of TaGLU1-1 and TaGLU4 genes, and a decline in mRNA abundance of the TaZOG2-1 gene (Table 2, Figure 8C,D). Taken together, our results reveal that NE of SnTox3 could affect CK metabolism only through activation of the ethylene signaling pathway-i.e., in an ethylene-dependent manner.

The CK level in the plant can be regulated by either decreasing or increasing the oxidative degradation of CK. An extreme increase in the transcript level of the TaCKX1 gene from 7- to 10-fold has been detected in SnTox3-sensitive Kaz10 plants pretreated with ET or not $24 \mathrm{~h}$ after infection with virulent SnB (Figure 8A). Importantly, 1-MCP pretreatment in the compatible Kaz10/SnB interaction only partially removed the effect of ethylene: about 2- to 4-fold mRNA accumulation of the TaCKX1 gene remained in the Kaz10/SnB/1-MCP variant at 6 and $24 \mathrm{hpi}$ (Figure $8 \mathrm{~A}$ ). In all other variants, in both cultivars upon infection, a similar tendency of the changes in the TaCKX1 gene transcription was detected-that is, the transcript level increased about two times at $6 \mathrm{hpi}$ and decreased at $24 \mathrm{hpi}$ compared to control plants (Figure 8). These results demonstrate that only the virulent SnB expressing SnTox3 gene was able to activate TaCKX1 in the susceptible genotype, while treatment with either ET or 1-MCP had a weak effect on TaCKX1 transcription. Thus, SnTox3-induced $\mathrm{TaCKX} 1$ transcription in both ethylene-dependent and ethylene-independent manner.

\subsection{Interaction of Signaling Pathways of Ethylene, $C K$, and $S A$}

We have studied individual elements involved in the signaling pathways of ethylene, $\mathrm{CK}$, and SA under the influence of treatment with ET, 1-MCP, SA, and trans-zeatin in plants 
of the Om35 and Kaz10 cultivars. In this work, we studied the TFs ERF1 (TaPIE1) and EIN3 (TaEIL1) as elements of the ethylene signaling pathway [50,51], the type-B cytokinin response regulator TaRR21 which is an ortholog of the Arabidopsis gene ARR2 [52], and TaWRKY13 as a marker of the development of the SA signaling pathway which is an ortholog of the Arabidopsis gene AtWRKY70 [53]. (Table S2, see Supplementary Materials).

Treatment with trans-zeatin and SA downregulated the expression of TaEIL1 and TaPIE1 in both SnTox3-sensitive Kaz10 and SnTox3-insensitive Om35 plants infected with virulent $\mathrm{SnB}$, indicating inhibition of the ethylene signaling pathway (Figure 9A,B). A similar nature of the transcription of genes was observed in infected plants of both varieties treated with 1-MCP (Figure 2). In SnTox3-insensitive Om35 plants and plants of both varieties treated with either trans-zeatin, SA or 1-MCP, the expression of TaWRKY13 increased (Figure 9C), suggesting induction of the SA signaling pathway in these plants. In the SnTox3-sensitive Kaz10 cultivar and plants of both cultivars treated with ET, we observed inhibition transcription of the TaWRKY13 gene (Figure 9C). These results indicate that CK-activated transcription of SAdependent genes and SnTox3-induced ethylene inhibited this response in plants infected with S. nodorum. Analysis of the transcriptional activity of the type-B RR genes showed that cytokinin signaling was not activated in SnTox3-sensitive Kaz10 plants and in plants of both cultivars treated with ET and infected with virulent SnB. The transcript level of the TaRR21 gene was decreased in these plants (Figure 9D). In SnTox3-insensitive Om35 plants and in plants of both cultivars treated with either trans-zeatin or 1-MCP and infected with virulent $\mathrm{SnB}$, the transcription of this gene was activated (Figure 9D). The level of transcripts of the TaRR21 gene increased about 2-3 times compared to the uninfected control (Figure 9D). These results suggest activation of cytokinin signaling.

(A)

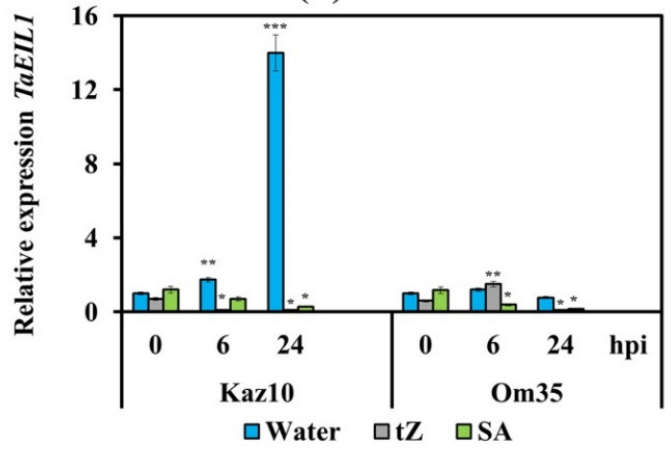

(C)

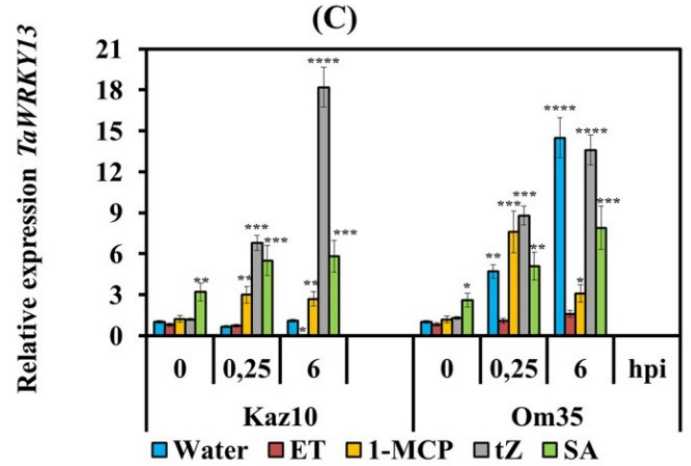

(B)



(D)

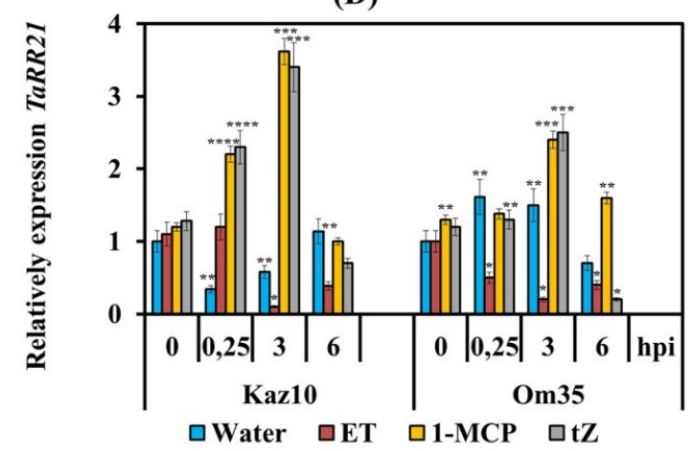

Figure 9. Interaction of signaling pathways of ethylene, cytokinin (CK) and SA in two wheat cultivars of Kaz10 and Om35 infected with virulent SnB. (A) The effect of pretreatment with $\mathrm{tZ}$ and SA on the relative expression of the TaEIL1 gene. (B) TaPIE1 gene. (C) The effect of pretreatment with ET, 1-MCP, tZ, and SA on the relative expression of the TaWRKY13 gene. (D) TaRR21 gene. Expression values are normalized to the housekeeping gene TaRLI as an internal reference and expressed relative to the normalized expression levels in mock-treated control (water) plants at 0 hpi. Symbols are the same as in Figures 2 and 5. Figures present means \pm SE $(n=6)$. Asterisks indicate means statistically different from the control and different number of asterisks allows $\left({ }^{*}, * *, * * * * * *\right)$ distinguishing of significantly different variants according to the LSD test at ${ }^{*} p<0.05,{ }^{* *} p<0.01,{ }^{* * *} p<0.001,{ }^{* * * *} p<0.0001$. 


\section{Discussion}

Although over the past 15 years significant progress has been made in cloning and characterizing the S. nodorum effectors SnToxA, SnTox1, and SnTox3 $[8,9]$ and the dominant wheat susceptibility genes Tsn1 and Snn1 [6,54], little is known about the effector responses and hormonal signaling pathways operating in the determination of wheat resistance. The few studies of the transcriptome and proteome of sensitive wheat genotypes have been carried out to investigate the impact of effectors on the plants defense response, showing both the activation and repression of a large number of genes upon toxin infiltration $[25,55]$. With regard to SnTox3, only one study of this type is known, in which the effect of SnTox3 on primary metabolism, photosynthetic proteins, and genes associated with signaling, redox metabolism, and ethylene synthesis in SnTox3-sensitive wheat genotype was shown using a comprehensive transcriptomic, proteomic, and metabolomic approach [25]. The results of this work revealed many interesting processes in the host plant associated with action to NE SnTox3. However, we now need to functionally characterize some of these processes and define exactly what role they play in disease.

\subsection{Stagonospora nodorum NE SnTox3 Induces Biosynthesis and Signaling Pathway of Ethylene}

In this study, we have used SnTox3-sensitive and SnTox3-insensitive wheat genotypes as well as two $S$. nodorum isolates expressing $(\mathrm{SnB})$ and nonexpressing (Sn4VD) genes encoding the host-specific necrotrophic effector SnTox3 to explore the SnTox3 interference with the hormonal signaling pathways of ethylene, CK, and SA. Our data showed that NE SnTox3 induced TaACS and TaACO genes involved in ethylene biosynthesis only in sensitive wheat genotypes due to gene-for-gene interactions (Figure 2). Our results are in accordance with the data published previously and obtained using the transcriptomic and proteomic approach [25]. Genes encoding aminocyclopropane synthase (ACS) and ACC oxidase (ACO), both involved in the synthesis of ethylene from S-adenosyl methionine (SAM), were upregulated in SnTox3-infiltrated plants [25]. These data clearly show that SnTox3 induces activation of ethylene biosynthesis in the susceptible wheat genotype. The induction of the ethylene signaling pathway by the SnTox 3 effector, manifested in the activation of the main positive regulator of this pathway EIN3 (TaEIL1) and the transcription factor ERF1 (TaPIE1), which we found in the susceptible wheat genotype is consistent with similar data previously published by other authors $[51,56]$.

Importantly, we found that the biosynthesis and signaling pathway of ethylene were only activated in the susceptible genotype and were not activated in the resistant genotype of wheat. These results suggest that ethylene plays a negative role in wheat defense to S. nodorum. This assumption is confirmed by our results obtained using pretreatments with the ethylene-releasing chemical ET or 1-MCP, a well-known ethylene receptor blocker, and is consistent with the data obtained by other authors, in which ethylene caused necrosis in plant tissues and contributed to the following colonization of the host plant by the pathogen $[12,51,57]$.

However, it is well known that treatment of plants with ethylene increases either susceptibility or resistance, depending on the plant-pathogen interaction, and on the conditions of the interaction. Thus, ethylene enhanced the resistance of rice to Magnaporthe oryzae [58], but increased the susceptibility of rice to Cochliobolus miyabeanus [12] and of wheat to Pyricularia oryzae [59]. The role of ethylene has been extensively studied using plant mutants affected in ethylene production or signaling [60]. However, contradictory results were obtained, indicating in some cases that ethylene can function as a virulence factor of certain pathogens and, in other cases, that it acts as a signaling molecule in defense response $[60,61]$. The ambivalent effect of ethylene can be explained by the following facts. First, ethylene regulates programmed cell death (PCD) both during the PTI and disease development. Second, the effects of ethylene at different stages of infection might also be quite different. Third, ethylene acts in conjunction with other phytohormones in synergistic or antagonistic interactions, on which the effect of ethylene may depend [62]. 


\subsection{Ethylene and Cytokinins Regulate ROS Production in Wheat Plants Infected with S. nodorum}

Our results showed that NE SnTox3 was involved in the development of necrosis in wheat tissues, appearing 4-6 days after infection, in an ethylene-dependent manner, which was confirmed by the treatment of plants with ethephon (Figure 1). However, we were interested in the roles of SnTox3 and ethylene in the suppression of plant defense reactions at the early stages of infection before the appearance of visible symptoms. Therefore, our study focused on researching the role of ethylene and its interaction with CK and SA in the regulation of ROS production during PTI and at the early stages of infection (24 hpi) of wheat plants with the pathogen S. nodorum.

\subsubsection{Ethylene Promotes Penetration and Growth of the S. nodorum Fungus in Wheat Tissues}

ROS production triggered by PAMPs in the apoplast through the activation of NADPH oxidases and peroxidases leads to PTI-dependent induction of programmed cell death (PCD) and inhibition of pathogen growth [10]. The function of $\mathrm{H}_{2} \mathrm{O}_{2}$ in suppressing the growth of pathogens is fully understood [10]. Plant ROS are powerful weapons against pathogens. However, pathogens, using effectors, can avoid unwanted cytotoxic ROS accumulation [10]. We found that a strong local accumulation of $\mathrm{H}_{2} \mathrm{O}_{2}$ and superoxide radicals in the epidermis and mesophyll cells at the sites of pathogen penetration stopped the growth of S. nodorum mycelium (Figure 4). The SnTox3-induced ethylene promoted a weak accumulation of superoxide radical and inhibition of $\mathrm{H}_{2} \mathrm{O}_{2}$ production, which led to the proliferation of fungal hyphae in wheat tissues (Figure 4). Similarly, inhibition of mycelium development in pathogen was found in transgenic plants with impaired synthesis or reception of ethylene, [12,16], and the inhibition of ethylene reception by 1-MCP led to an increase in $\mathrm{H}_{2} \mathrm{O}_{2}$ content in the apoplast [63]. It has also been shown that low concentrations of ROS are inducers of morphogenesis in fungi, contributing to their enhanced growth and development [64], and pathogens use phytohormonal signaling pathways in plants to regulate the ROS level $[13,65]$. Additionally, a direct dependence of the growth rate and spread of the pathogen on the production of ethylene and low ROS concentrations was shown in tobacco plants infected with Phytophthora parasitica var nicotianae [57].

Our results show that the rapid production of $\mathrm{H}_{2} \mathrm{O}_{2}$ in resistant SnTox3-insensitive plants and in plants treated with 1-MCP to disrupt ethylene signaling can inhibit the proliferation of fungal mycelium and allow the plant to induce defense mechanisms to effectively stop the pathogen's penetration into the mesophyll. This suggests that the S. nodorum, despite a purely necrotrophic lifestyle, can have a short biotrophic phase in the epidermis, during which it is sensitive to $\mathrm{H}_{2} \mathrm{O}_{2}$-dependent protection, and the function of NE SnTox3 is to create favorable conditions for fungal growth and plant colonization by suppressing oxidative burst at an early stage of infection in an ethylene-dependent manner.

4.2.2. Ethylene Inhibited Biphasic $\mathrm{H}_{2} \mathrm{O}_{2}$ Production and Cytokinins Induced It at Early Stages of Infection with $S$. nodorum

ROS induced by PAMPs also act as signaling molecules, mediating responses of plant cells to pathogen attacks $[10,43,66]$. The $\mathrm{H}_{2} \mathrm{O}_{2}$ molecule is uncharged, relatively long-living, and can penetrate through membranes; therefore, it is the most suitable candidate for the role of a secondary messenger [43]. We found that the accumulation of $\mathrm{H}_{2} \mathrm{O}_{2}$ with two peaks at 6 and 24 hpi was characteristic of resistant SnTox3-insensitive plants, while the biphasic character of $\mathrm{H}_{2} \mathrm{O}_{2}$ production was absent in susceptible plants and plants treated with ethephon (Figure 3).

Biphasic ROS production or "ROS wave" has been reported in many incompatible plant-pathogen interactions [57,67] as well as in case of abiotic stresses [68]. The first (early) peak occurs within minutes and hours, and the second (long term) one appears within a day after the onset of the stimulus [66]. Modern studies have shown that the first (early) peak in ROS production can trigger a cascade of subsequent reactions, form a long-term ROS signal, and is an important factor in disease resistance [66]. The induction of hormonal signaling 
pathways is also consistent with the phase character of $\mathrm{H}_{2} \mathrm{O}_{2}$ accumulation $[69,70]$. It has been previously shown that SA is closely related to the induction and enhancement of the first phase of $\mathrm{H}_{2} \mathrm{O}_{2}$ production and the further development of systemic resistance [69]. Our recent publication showed the induction of SA signaling and increases in expression of the marker genes PR-1 and PR-2 during incompatible interactions and inhibition of SA signaling during compatible interactions and under the influence of ethylene in the wheatS. nodorum pathosystem [28]. In this work, pretreatment with SA of SnTox3-sensitive plants induced the biphasic character of $\mathrm{H}_{2} \mathrm{O}_{2}$ production with peaks at 6 and 24 hpi with $\mathrm{SnB}$; an increase in transcripts of the SA pathway marker genes of the $P R-1$ and $P R-2$ was also found (Figure 7). An assumption was made in which ROS and SA function together in a self-amplifying feedback loop, in which ROS induce SA accumulation and SA subsequently enhances ROS accumulation [71].

Interestingly, the same biphasic $\mathrm{H}_{2} \mathrm{O}_{2}$ production and induction of transcription of the $P R-1$ and $P R-2$ genes were found in SnTox3-sensitive plants pretreated with transzeatin (Figures 5 and 7), suggesting activation of the SA pathway by trans-zeatin which is consistent with findings of other authors. [17]. Such a positive effect of trans-zeatin on the ROS generation in plants is not a surprise because the role of various forms of exogenous CKs (kinetin, 6-benzylaminopurine, trans-zeatin) in the induction of ROS generation during the regulation of growth and development processes, as well as responses to stress factors, was shown in various plant and cell cultures $[45,47,72]$. Thus, our data clearly indicate that cytokinins induce an SA-dependent resistance mechanism in wheat against $S$. nodorum associated with biphasic $\mathrm{H}_{2} \mathrm{O}_{2}$ production at the early stages of infection, while ethylene inhibits this defense mechanism. Finally, the antagonism of CK and ethylene manifested itself at the level of ROS production and led to the opposite influence on the SA-dependent resistance mechanism.

4.2.3. SnTox3, Ethylene and Cytokinins Regulate the Work of Redox Enzymes in Wheat Plants Infected with $S$. nodorum

Apoplast-secreted peroxidases [73] and membrane-bound NADPH oxidases [74] perform significant roles in plant oxidative bursts [43]. We studied two isoforms of wheat NADPH oxidase, RBOHD and RBOHF, which are not comprehensively studied, akin to the AtRboh Arabidopsis genes. Nevertheless, there are works showing that the TaRbohD and TaRbohF genes, which are homologues of the Arabidopsis genes AtRbohD and $A t R b o h F$ and activated under biotic stress, are involved in the production of ROS, and the early peak of $\mathrm{H}_{2} \mathrm{O}_{2}$ production depends on TaRbohD [75]. Our results showed that the two isoforms of NADPH oxidase, RBOHD and RBOHF, perform different functions during the defense response of wheat against $S$. nodorum. The incompatible interaction was characterized by an earlier transcript accumulation of the TaRbohD gene and a late increase in mRNA abundance of the TaRbohF gene, which coincided with the two peaks of $\mathrm{H}_{2} \mathrm{O}_{2}$ production (Figures 3 and 6). Our data are consistent with the results described in the literature for most pathosystems, which indicates a qualitative (spatial or temporal) difference in the ROS produced by each AtRboh [57,75-77]. The use of various mutants of the model Arabidopsis plants showed that $A t R b o h D$ is responsible for rapid ROS production during PTI in the first minutes and hours after plant recognition of PAMPs and its activation is PAMP-mediated [44]. The high levels of ROS in the first peak induce AtRbohF, which affects intracellular oxidative stress, intercellular signal transmission, and genome reprogramming-i.e., development of systemic resistance [77]. Moreover, SA is required to maintain $A t R b o h F$ expression and AtRbohF ensures sustained SA accumulation [77].

The obtained results show that SA and CK induced early activation of TaRbohD transcription and late activation of TaRbohF transcription (Figure 6). This caused an incompatibility reaction in susceptible plants and the development of resistance along the SA-dependent pathway, as indicated by the induction of expression of SA pathways marker genes PR-1 and PR-2 (Figure 7). On the contrary, SnTox3 inhibited TaRbohF transcription specifically through gene-for-gene interactions in ethylene-dependent and ethyleneindependent manners, which is confirmed by the treatment of plants with either ethephone 
or 1-MCP (Figure 3). This led to extensive lesions and the absence of SA-dependent defense reactions, suggesting that TaRbohF performs functions similar to AtRbohF in induction of the SA signaling pathway and limits lesions [77].

The observed slight increase in the TaRbohD gene transcripts at 6 hpi during compatible interactions and under the influence of ET treatment was not associated with oxidative burst and can explain the small accumulation of superoxide radicals in mesophyll cells under stomata, which ensured the penetration and growth of the pathogen. Our data showed that the massive increase in the TaRbohD gene transcripts at $24 \mathrm{hpi}$ in SnTox3-sensitive plants was not associated with the $\mathrm{H}_{2} \mathrm{O}_{2}$ production and the development of defense reactions (Figure 3). However, these results can be explained by the reports demonstrating the ability of AtRbohD-dependent ROS production to suppress salicylate-mediated cell death at the sites of pathogen penetration, thereby ensuring the spread of infection [78]. Our data strongly suggest an ethylene-dependent way of TaRbohD transcription regulation by the SnTox3 effector in wheat at the early stages of $S$. nodorum infection, which is consistent with the literature data on the regulation of $A t R b o h D$ expression by ethylene [79].

The class III peroxidases are the most ubiquitous plant enzymes. They form an important part of ROS homeostasis in plant-microbial interactions, and occupy one of the key positions in plant defense against pathogens [80]. Our recent publication showed that ET treatment reduced the activity of peroxidases and the transcription of the anionic peroxidase gene in the resistant cultivar Om35 infected with S. nodorum, which was accompanied by decreased ROS production [28]. Interestingly, treatment with 1-MCP completely canceled the ethylene effect on the peroxidases activity during infection [28]. Our data coincide with works proving the inhibitory effect of ethylene on peroxidases under the action of a stress factor [81-84]. The role of CKs in the regulation of redox enzymes under influence of various stress factors, including biotic ones, has not been sufficiently studied; the data found in the literature are scarce, but in some studies it has been shown that CKs increased activity of peroxidases involved in the ROS generation during pathogenesis [47]. Thus, our results on the increase in peroxidase activity under influence of treatment with trans-zeatin are consistent with some literature data.

It has been established that some mechanisms of a decrease in the $\mathrm{H}_{2} \mathrm{O}_{2}$ concentration during pathogenesis are associated with catalase activation [66]. Catalases enhance the virulence of fungal pathogens, including $S$. nodorum, by reducing the ROS concentration in the infected zone and suppressing oxidative burst [85]. We have previously shown that increased catalase activity was a characteristic feature of wheat plants treated with ET and infected with $S$. nodorum, being the cause of low $\mathrm{H}_{2} \mathrm{O}_{2}$ production in wheat at the early stages of infection [28]. The role of ethylene in the regulation of catalase activity has not been well understood, especially under biotic stress, but some studies have shown that ethylene is able to activate catalase $[81,82,86]$. Importantly, SA is known to inhibit catalase activity leading to an increase in the $\mathrm{H}_{2} \mathrm{O}_{2}$ concentration and the development of an oxidative burst, which plays an important role in the system defense antipathogenic reactions of plants [87]. In our work, both SA and trans-zeatin treatment led to a strong decrease in catalase activity in wheat at the early stages of S. nodorum infection (Figure 6). This was accompanied by biphasic $\mathrm{H}_{2} \mathrm{O}_{2}$ production (Figure 5).

Thus, in the wheat-S. nodorum pathosystem, the antagonism of ethylene on the one hand and CK and SA on the other hand at the early stages of infection manifested itself in the effect on redox enzymes-NADPH oxidase, peroxidase, and catalase.

\subsection{SnTox3 and Ethylene Inhibited Biosynthesis, Modulated Metabolism, and Activated Oxidative Degradation of Cytokinins}

One of the important approaches decoding the role of phytohormones in plant immunity is the study of phytohormone crosstalk. In the last decade, the important role of the interactions of CK with SA $[17,88]$ and ABA [19] with auxins [89,90] in plant immunity has been established. Unfortunately, CK-ethylene crosstalk in the defense response has not been studied. Cytokinins are the most important class of phytohormone stimulants that promote active metabolism and plant growth $[46,91]$. Previously, cytokinins were 
considered in the plant-pathogen interactions, only as hormones produced by pathogens and necessary for their nutrition and development [92]. The role of CK in the induction of plant defense had been recognized only in the late 2000s [17,93]. Currently, data have been accumulated on the role of CK in the development of plant resistance to biotrophic [94], hemibiotrophic $[17,95]$, and necrotrophic $[96,97]$ pathogens of bacterial or fungal origin, as well as viruses [98]. Nevertheless, the regulatory mechanism and targets of cytokinins during defense responses to pathogens are still elusive. It has been shown that CK can contribute to plant resistance through the regulation of SA-dependent defense reactions, including upregulation of a number of genes encoding protective proteins $[17,18,88,93]$, as well as through the SA-independent pathway leading to the synthesis of phytoalexins and lignification processes $[23,95]$. In this work, we have found that resistance reactions involved in incompatible interactions are characterized by an increase in the content of active CK brought about by de novo synthesis of CK, their release from bound forms and the absence of an increase in their oxidative degradation. Susceptibility reactions that occur during compatible interactions involve a decline in the content of active CK due to a decrease in the CK synthesis, increase in the irreversible oxidation of $\mathrm{CK}$, and conversion of active CK into inactive forms (Z-9G and Z-OG).

4.3.1. SnTox3 and Ethylene Regulated Cytokinin Biosynthesis in Wheat Plants Infected with S. nodorum

First of all, our results clearly indicate that the incompatible interaction was characterized by an increased level of CK active forms in wheat leaves at the initial stage of infection (24 hpi) associated with the induction of oxidative burst and the triggering SA-dependent defense reactions. The compatible interaction was characterized by a directed decrease in the contents of $\mathrm{CK}$ active forms due to the regulation of CK biosynthesis, glucosylation, and oxidative degradation by the SnTox3 effector (Table 1). In plants, isopentenyltransferases (IPTs) are considered to be the rate limiting enzyme in cytokinin biosynthesis [48]. We found that the pathogen S. nodorum suppressed transcription of TaIPT genes in wheat using NE SnTox3 specifically by gene-for-gene interactions in ethylene-dependent and ethyleneindependent manners (Figure 8). In the present work, it was shown for the first time that NE SnTox3 interfered, possibly indirectly, in the hormonal pathway of CKs and suppressed their biosynthesis. One of these indirectly mediated mechanisms was the ethylene signaling pathway, which is activated by the SnTox 3 effector. It has been known that CKs in some cases play a negative role in the regulation of ethylene biosynthesis. For example, delays in flowering correlating with the increases in CK levels and delays in ethylene biosynthesis were observed in petunia [99]. The possibility that ethylene may affect CK biosynthesis is also being considered, although there is little empirical confirmation for this hypothesis as yet [100]. However, there are reports showing an increased expression of the AtIPT3 gene and accumulation of CK in roots in ethylene-insensitive etr1-1 mutants [101], which may indirectly indicate the possible inhibition of CK biosynthesis by ethylene.

\subsubsection{SnTox3 and Ethylene Activated Oxidative Degradation of Cytokinins in Wheat} Plants Infected with S. nodorum

Some studies suggested that pathogens are able to alter CK levels in host plants through the effect on cytokinin oxidases/dehydrogenases (CKXs) [97,102,103] involved in the irreversible oxidation of CKs [104]. Our results showed that pathogen S. nodorum induced transcription of the CKX1 gene in wheat using NE SnTox3 specifically by genefor-gene interactions in ethylene-dependent and ethylene-independent manners, which correlated with a low level of active CKs in wheat leaves. Our results are consistent with the data obtained on Arabidopsis plants infected with the soilborne fungus Verticillium longisporum, which induced transcription of the AtCKX genes leading to a decrease in the $\mathrm{Z}$ level and the development of necrosis and chlorosis in the leaves [97]. However, it has not been determined as to whether this resulted from the action of effectors secreted by the pathogen. Wan et al. (2019) showed that the effector AvrL567-A from the flax rust fungus Melampsora lini interacted with a flax cytosolic cytokinin oxidase, $L u C K X 1.1$, increased 
its catalytic activity, and reduced the cytosolic cytokinin levels, thereby promoting the colonization of the plant [103]. Moreover, indirect activation of CKX is possible through interference with the hormonal pathways of the plant. In the literature, there are data showing activation of CKX by ethylene during organ abscission [105]. Auxins and ABA are also capable of activating CKX during drought [106] or infection [102]. We speculate that the ethylene-independent mechanism of CKX activation could be via the hormonal pathways IAA or ABA.

4.3.3. SnTox3 and Ethylene Modulated Metabolism of Cytokinins in Wheat Plants Infected with $S$. nodorum

The glucosylation reaction (conjugation to sugars) is one of the effective ways to reduce the level of active CKs in plants. Glucosylation of CK at the N3, N7, and N9 positions of the purine moiety forms $\mathrm{N}$-glucosides and their synthesis is practically irreversible. Glucosylation of CK at the hydroxyl group of the side chains of $t Z, D Z$, and $c Z$ results in production of O-glucosides the process being reversible. O-glucosides are considered as temporarily storage forms of CKs; from which active forms are released by deglycosylation catalyzed by $\beta$-glucosidase (GLU) [48,49]. The glucosylation reaction has been well studied during senescence processes [49,107]. A dramatic increase in TaZOG expression observed during leaf senescence was accompanied by accumulation of CK O-glucosides in leaves [49]. In one of the few studies, accelerated conversion of active cytokinins into O-glucosides was shown in plants treated with ethylene leading to faster Petunia corolla senescence [107]. In another work, a positive effect of ethylene on the irreversible glucosylation of active $\mathrm{CK}$ to 9-N-glucosides was detected [101]. In our experiments, showing upregulation of TaZOG2-1 gene and inhibition of TaGLU4 gene transcription by ET led to an increase in the Z-9G and Z-OG contents and a decrease in active CK in infected leaves, which is consistent with the literature data. However, we have shown for the first time that the glucosylation reaction was induced, and deglucosylation reaction was suppressed by NE of SnTox3 only in an ethylene-dependent manner. In the incompatible interaction, on the contrary, the deglucosylation reaction was induced and the CK biosynthesis was activated. We speculate that these processes could have been triggered by PAMPs.

\subsection{Ethylene Induced by the Effector SnTox3 Suppresses the SA Signaling Pathway and Cytokinins Trigger it in Wheat Plants Infected with S. nodorum}

Over the past decade, the molecular mechanisms mediating CK-ethylene crosstalk at various levels of biosynthetic and metabolic pathways, as well as their complex interactions with growth processes and in response to environmental stressors, have been actively studied [22,100,108-112]. Nevertheless, it remains unclear how individual signals are integrated into a unified plant response to a certain stimulus.

Our results show that resistance was associated with activation of the CK signaling pathway. This led to the induction of SA signaling pathway genes and suppression of the transcription of ethylene response genes. The susceptibility was associated with the development of the ethylene signaling pathway, which suppressed the activation of the primary response CK gene of the RR factor. This led to inhibition of the expression of CK-dependent genes. Our results clearly indicate antagonistic interaction between SA and ethylene in the wheat-S. nodorum pathosystem, similar to what has been shown for Arabidopsis thaliana infected with Pseudomonas syringae pv tomato DC3000 [16]. We discovered that the ethylene-SA antagonism was implemented through the ethylene impact on the CK. At the same time, this does not exclude ethylene effect on the SA, because the negative action of ethylene signaling on SA biosynthesis has been shown [16]. Our results also suggest cytokinin-SA synergism, which follows from a similar plant response to SA or trans-zeatin treatment during infection with S. nodorum (Figures 5-7). The synergistic interaction between SA and CK has been shown for some pathosystems $[17,88,97,102]$. These studies have presented that an increase in CK levels and CK signaling activation leads to an enhanced immunity by the acceleration of the defense plant response through the SA pathway. The type-B cytokinin response regulator ARR2 is known to interact with SA 
signalling pathway protein TGA3 (a bZIP transcription factor), which induces expression of defense related genes by binding to their promoters $[17,113,114]$. Thus, cytokinin-activated type-B RRs play a significant role in hormone crosstalk [112].

We found that NE SnTox3 induced biosynthesis and the signaling pathway of ethylene, which suppressed CK and SA signaling at the early stages of infection. This is indicated by the inhibition of the transcription of TaWRKY13 and TaRR21 genes in the SnTox3-sensitive Kaz10 plants and plants treated with ET and infected with virulent SnB (Figure 9). In contrast, treatment with either SA or trans-zeatin induced TaWRKY13 and TaRR21 gene transcription and suppressed ethylene signaling. This is indicated by the inhibition of EIN3 (TaEIL1) and ERF1 (TaPIE1) gene transcription in the SnTox3-insensitive Om35 plants and plants treated with either SA or trans-zeatin and infected with virulent SnB (Figure 9). Our results are consistent with some studies, which showed that CK treatment regulated the expression of the TFs WRKY and ERF $[115,116]$. Some WRKYs can control the expression of NPR1, required for CK- and SA-mediated defense crosstalk, as npr1 mutants did not show increased CK resistance upon exogenous application of trans-zeatin [89]. We found that the increase in transcription levels of the TaWRKY13 and TaRR21 genes preceded the increase in mRNA level of the $P R-1$ and $P R$-2 genes in the SnTox3-insensitive Om35 plants and plants treated with SA or trans-zeatin and infected with virulent SnB (Figures 7 and 9), which coincides with the data of other authors [117]. Thereby, our results suggest that TaWRKY13, TaRR21, EIN3 (TaEIL1), and ERF1 (TaPIE1) are hubs of the ethylene-SA-CK crosstalk in the wheat-S. nodorum pathosystem. In summary, NE SnTox3 activated ethylene signaling and suppressed CK signaling, which increased the susceptibility of wheat to S. nodorum. Thus, crosstalk between ethylene and cytokinins determines resistance/susceptibility of wheat plants to S. nodorum.

\section{Conclusions}

We showed that SnTox3 inhibited PTI responses, including ROS production and SA-dependent defense responses by manipulating ethylene signaling in plants infected with S. nodorum. In turn, the ethylene signaling pathway affected the enzymes of redox metabolism by suppressing the oxidative burst and thereby creating favorable conditions for the development of the pathogen. Furthermore, the ethylene signaling pathway interfered with the cytokinin signaling pathway, while the latter induced an oxidative burst and SA-dependent defense response and ultimately led to the development of PTI. For the first time, we have shown that NE SnTox3 inhibits biosynthesis, modulates metabolism, and activates oxidative degradation of cytokinins in ethylene-dependent and ethyleneindependent manners at the early stages of infection, which shows the critical role of CK in the regulation of plant immunity. It is worth paying attention to the fact that in the case of inhibition of biosynthesis and activation of degradation of cytokinin, SnTox3 could act independently of ethylene. Further experiments will help identify these mechanisms, which may be associated with crosstalk of the cytokinins with other hormonal signaling pathways. Further study of the mechanisms of hormone crosstalk in the wheat-S. nodorum pathosystem will help to reveal the general mechanisms of resistance/susceptibility of plants to NE producing pathogens. Such information will make an important contribution to the development of Marker-Associated Breeding (MAB).

Supplementary Materials: The following are available online at https:/ / www.mdpi.com/2218-273 X/11/2/174/s1, Table S1. Primers used for qPCR. Table S2. The lists of orthologous genes used in this work.

Author Contributions: Conceptualization, S.V.V.; methodology, S.V.V., T.V.N., G.F.B., and S.D.R.; software, S.V.V. and G.F.B.; data curation, S.V.V.; writing-original draft preparation, S.V.V.; writingreview and editing, E.K.K. and I.V.M.; supervision and project administration, S.V.V.; funding acquisition, E.K.K. All authors have read and agreed to the published version of the manuscript.

Funding: This work was supported by State Project AAAA-A16-116020350027-7 and the Russian Foundation for Basic Research, project number 18-04-00978 and number 20-316-80047. 
Conflicts of Interest: The authors declare no conflict of interest.

\section{References}

1. Robert-Seilaniantz, A.; Grantm, M.; Jones, J.D. Hormone crosstalk in plant disease and defense: More than just jasmonate-salicylate antagonism. Annu. Rev. Phytopathol. 2011, 49, 317-343. [CrossRef] [PubMed]

2. Akhtar, S.S.; Mekureyaw, M.F.; Pandey, C.; Roitsch, T. Role of cytokinins for interactions of plants with microbial pathogens and pest insects. Front. Plant Sci. 2020, 10, 1777. [CrossRef] [PubMed]

3. Jones, J.D.G.; Dang, J.L. The plant immune system. Nature 2006, 444, 323-329. [CrossRef] [PubMed]

4. Oliver, R.P.; Solomon, P.S. New developments in pathogenicity and virulence of necrotrophs. Curr. Opin. Plant Biol. 2010, 13, 415-419. [CrossRef]

5. Friesen, T.L.; Faris, J.D. Characterization of the wheat-Stagonospora nodorum disease system: What is the molecular basis of this quantitative necrotrophic disease interaction? Can. J. Plant Pathol. 2010, 32, 20-28. [CrossRef]

6. Shi, G.; Zhang, Z.; Friesen, T.L.; Raats, D.; Fahima, T.; Brueggeman, R.S.; Lu, S.; Trick, H.N.; Liu, Z.; Chao, W.; et al. The hijacking of a receptor kinase-driven pathway by a wheat fungal pathogen leads to disease. Sci. Adv. 2016, 2, e1600822. [CrossRef]

7. Phan, H.T.T.; Rybak, K.; Furuki, E.; Breen, S.; Solomon, P.S.; Oliver, R.P.; Tan, K.C. Differential effector gene expression underpins epistasis in a plant fungal disease. Plant J. 2016, 87, 343-354. [CrossRef]

8. McDonald, M.C.; Solomon, P.S. Just the surface: Advances in the discovery and characterization of necrotrophic wheat effectors. Curr. Opin. Microbiol. 2018, 46, 14-18. [CrossRef]

9. Liu, Z.; Zhang, Z.; Faris, J.D.; Oliver, R.P.; Syme, R.; McDonald, M.C.; McDonald, B.A.; Solomon, P.S.; Lu, S.; Shelver, W.L.; et al. The cysteine rich necrotrophic effector SnTox1 produced by Stagonospora nodorum triggers susceptibility of wheat lines harboring Snn1. PLoS Pathog. 2012, 8, e1002467. [CrossRef]

10. Jwa, N.-S.; Hwang, B.K. Convergent evolution of pathogen effectors toward reactive oxygen species signaling networks in plants. Front. Plant Sci. 2017, 8, 1687. [CrossRef]

11. Shigenaga, A.M.; Berens, M.L.; Tsuda, K.; Argueso, C.T. Towards engineering of hormonal crosstalk in plant immunity. Curr. Opin. Plant Biol. 2017, 38, 164-172. [CrossRef] [PubMed]

12. Vleesschauwer, D.; Yang, Y.; Cruz, C.V.; Hofte, M. Abscisic acid-induced resistance against the brown spot pathogen Cochliobolus miyabeanus in rice involves MAP kinase-mediated repression of ethylene signaling. Physiol. Plant 2010, 152, 2036-2052. [CrossRef] [PubMed]

13. Kazan, K.; Lyons, R. Intervention of phytohormone pathways by pathogen effectors. Plant Cell 2014, 26, 2285-2309. [CrossRef] [PubMed]

14. Broekgaarden, C.; Caarls, L.; Vos, I.A.; Pieterse, C.M.J.; van Wees, S.C.M. Ethylene: Traffic controller on hormonal crossroads to defense. Plant Physiol. 2015, 169, 2371-2379. [CrossRef] [PubMed]

15. Spoel, S.H.; Johnson, J.S.; Dong, X. Regulation of tradeoffs between plant defenses against pathogens with different lifestyles. Proc. Natl. Acad. Sci. USA 2007, 104, 18842-18847. [CrossRef]

16. Chen, X.; Steed, A.; Travella, S.; Keller, B.; Nicholson, P. Fusarium graminearum exploits ethylene signalling to colonize dicotyledonous and monocotyledonous plants. New Phytol. 2009, 182, 975-983. [CrossRef]

17. Choi, J.; Huh, S.U.; Kojima, M.; Sakakibara, H.; Paek, K.H.; Hwang, I. The Cytokinin-activated transcription factor ARR2 promotes plant immunity via TGA3/NPR1-dependent salicylic acid signaling in Arabidopsis. Dev. Cell 2010, 19, 284-295. [CrossRef]

18. Argueso, C.T.; Ferreira, F.J.; Epple, P.; To, J.P.C.; Hutchison, C.E.; Schaller, G.E.; Dangl, J.L.; Kieber, J.J. Two-component elements mediate interactions between cytokinin and salicylic acid in plant immunity. PLoS Genet. 2012, 8, e1002448. [CrossRef]

19. Großkinsky, D.K.; Albacete, A.; Jammer, A.; Krbez, P.; van der Graaff, E.; Pfeifhofer, H.; Roitsch, T. A rapid phytohormone and phytoalexin screening method for physiological phenotyping. Mol. Plant 2014, 7, 1053-1056. [CrossRef]

20. Shigenaga, A.; Argueso, C. No hormone to rule them all: Interactions of plant hormones during the responses of plants to pathogens. Semin. Cell Dev. Biol. 2016, 56, 174-189. [CrossRef]

21. Sharipova, G.V.; Veselov, D.S.; Kudoyarova, G.R.; Timergalin, M.D.; Wilkinson, S. Effect of ethylene perception inhibitor on growth, water relations, and abscisic acid content in wheat plants under water deficit. Russ. J. Plant Physiol. 2012, 59, 573-580. [CrossRef]

22. Smets, R.; Le, J.; Prinsen, E.; Verbelen, J.-P.; van Onckelen, H.A. Cytokinin-induced hypocotyl elongation in light-grown Arabidopsis plants with inhibited ethylene action or indole-3-acetic acid transport. Planta 2005, 221, 39-47. [CrossRef]

23. O'Brien, J.A.; Benková, E. Cytokinin cross-talking during biotic and abiotic stress responses. Front. Plant Sci. $2013,4,451$. [CrossRef] [PubMed]

24. Han, X.; Kahmann, R. Manipulation of phytohormone pathways by effectors of filamentous plant pathogens. Front. Plant Sci. 2019, 10, 822. [CrossRef]

25. Winterberg, B.; Du Fall, L.A.; Song, X.M.; Pascovici, D.; Care, N.; Molloy, M.; Ohms, S.; Solomon, P.S. The necrotrophic effector protein SnTox3 re-programs metabolism and elicits a strong defence response in susceptible wheat leaves. BMC Plant Biol. 2014, 14, 215. [CrossRef] [PubMed]

26. Breen, S.; Williams, S.J.; Outram, M.; Kobe, B.; Solomon, P.S. Emerging insights into the functions of pathogenesis related protein. Trends Plant Sci. 2017, 22, 10. [CrossRef] [PubMed] 
27. Veselova, S.V.; Nuzhnaya, T.V.; Maksimov, I.V. The Effect of 1-methylcyclopropene on the components of pro and antioxidant systems of wheat and the development of defense reactions in fungal pathogenesis. Appl. Biochem. Microbiol. 2014, 50, 516-523. [CrossRef]

28. Veselova, S.V.; Burkhanova, G.F.; Nuzhnaya, T.V.; Maksimov, I.V. Roles of ethylene and cytokinins in development of defense responses in Triticum aestivum plants infected with Septoria nodorum. Russ. J. Plant Physiol. 2016, 63, 609-619. [CrossRef]

29. Veselova, S.V.; Burkhanova, G.F.; Nuzhnaya, T.V.; Rumyantsev, S.D.; Maksimov, I.V. Effect of the host-specific toxin SnTOX3 from Stagonospora nodorum on ethylene signaling pathway regulation and redox-state in common wheat. Vavilovskii Zhurnal Genet. Sel. Vavilov, J. Genet. Breed. 2019, 23, 856-864. [CrossRef]

30. Vysotskaya, L.; Wilkinson, S.; Davies, W.J.; Arkhipova, T.; Kudoyarova, G. The effect of competition from neighbours on stomatal conductance in lettuce and tomato plants. Plant Cell Environ. 2011, 34, 729-737. [CrossRef]

31. Warner, H.L.; Leopold, A.C. Ethylene evolution from 2-chloroethylphosphonic acid. Plant Physiol. 1969, 44, 156-158. [CrossRef] [PubMed]

32. Babosha, A.V. Characteristics of dose-response dependence between zeatin and susceptibility of wheat seedlings to powdery mildew. Biol. Bull. 2012, 39, 534-541. [CrossRef]

33. Ozeretskovskaya, O.L.; Vasyukova, N.I.; Chalenko, G.I.; Gerasimova, N.G.; Panina, Y.S.; Varlamov, V.P. Influence of systemic signal molecules on the rate of spread of the immunizing effect of elicitors over potato tissues. Appl. Biochem. Microbiol. 2004, 40, 213-216. [CrossRef]

34. Troshina, N.B.; Yarullina, L.G.; Valeev, A.S.; Maksimov, I.V. Salicylic acid induces resistance to Septoria nodorum Berk. in Wheat. Izv. Akad. Nauk. Seriia Biol. Ross. Akad. Nauk. 2007, 34, 545-550. [CrossRef]

35. Maximov, I.V.; Abizgildina, P.P.; Sorokan, A.V.; Burkhanova, G.F. Regulation of peroxidase activity under the influence of signaling molecules and Bacillus subtilis 26D in potato plants infected with Phytophthora infestans. Appl. Biochem. Microbiol. 2014, 50, 173-178. [CrossRef]

36. Bindschedler, L.V.; Minibaeva, F.; Gardner, S.L.; Gerrish, C.; Davies, D.R.; Bolwell, G.P. Early signalling events in the apoplastic oxidative burst in suspension cultured French bean cells involve cAMP and Ca ${ }^{2+}$. New Phytol. 2001, 151, 185-194. [CrossRef]

37. Thordal-Christensen, H.; Zhangt, Z.; Wei, Y.; Collinge, D.B. Subcellular localization of $\mathrm{H}_{2} \mathrm{O}_{2}$ in plants. $\mathrm{H}_{2} \mathrm{O}_{2}$ accumulation in papillae and hypersensitive response during the barley-powdery mildew interaction. Plant J. 1997, 11, 1187-1194. [CrossRef]

38. Wang, Y.; Shen, W.; Chan, Z.; Wu, Y. Endogenous cytokinin overproduction modulates ROS homeostasis and decreases salt stress resistance in Arabidopsis thaliana. Front. Plant Sci. 2015, 6, 1004. [CrossRef]

39. Plotnikova, L.Y.; Shtubey, T.Y. Influence of salicylic and succinic acids on the cytophysiological reactions of wheat infected by brown rust. Tsitologiia 2009, 51, 43-52.

40. Veselov, S.Y.; Timergalina, L.N.; Akhiyarova, G.R.; Kudoyarova, G.R.; Korobova, A.V.; Ivanov, I.; Arkhipova, T.N.; Prinsen, E. Study of cytokinin transport from shoots to roots of wheat plants is informed by a novel method of differential localization of free cytokinin bases or their ribosylated forms by means of their specific fixation. Protoplasma 2018, 255, 1581-1594. [CrossRef]

41. Arkhipova, T.N.; Veselov, S.U.; Melentiev, A.I.; Martynenko, E.V.; Kudoyarova, G.R. Ability of bacterium Bacillus subtilis to produce cytokinins and to influence the growth and endogenous hormone content of lettuce plants. Plant Soil 2005, 272, 201-209. [CrossRef]

42. Kudoyarova, G.R.; Korobova, A.V.; Akhiyarova, G.R.; Arkhipova, T.N.; Zaytsev, D.Y.; Prinsen, E.; Egutkin, N.L.; Medvedev, S.S.; Veselov, S.Y. Accumulation of cytokinins in roots and their export to the shoots of durum wheat plants treated with the protonophore carbonyl cyanide m-chlorophenylhydrazone (CCCP). J. Exp. Bot. 2014. 65, 2287-2294. [CrossRef]

43. Podgórska, A.; Burian, M.; Szal, B. Extra-cellular but extra-ordinarily important for cells: Apoplastic reactive oxygen species metabolism. Front. Plant Sci. 2017, 8, 1353. [CrossRef] [PubMed]

44. Kadota, Y.; Shirasu, K.; Zipfe, C. Regulation of the NADPH oxidase RBOHD during plant immunity. Plant Cell Physiol. 2015, 56, 1472-1480. [CrossRef] [PubMed]

45. Kunikowska, A.; Byczkowska, A.; Doniak, M.; Kaźmierczak, A. Cytokinins résumé: Their signaling and role in programmed cell death in plants. Plant Cell Rep. 2013, 32, 771-780. [CrossRef] [PubMed]

46. Romanov, G.A. How do cytokinins affect the cell? Russ. J. Plant Physiol. 2009, 56, 268-290. [CrossRef]

47. Arnaud, D.; Lee, S.; Takebayashi, Y.; Choi, D.; Choi, J.; Sakakibara, H.; Hwanga, I. Cytokinin-mediated regulation of reactive oxygen species homeostasis modulates stomatal immunity in Arabidopsis. Plant Cell 2017, 29, 543-559. [CrossRef]

48. Sakakibara, H. Cytokinins: Activity, biosynthesis, and translocation. Annu. Rev. Plant Biol. 2006, 57, 431-449. [CrossRef]

49. Song, J.; Jiang, L.; Jameson, P.E. Co-ordinate regulation of cytokinin gene family members during flag leaf and reproductive development in wheat. BMC Plant Biol. 2012, 12, 78. [CrossRef]

50. An, F.; Zhao, Q.; Ji, Y.; Li, W.; Jiang, Z.; Yu, X.; Zhang, C.; Han, Y.; He, W.; Liu, Y.; et al. Ethylene-Induced stabilization of

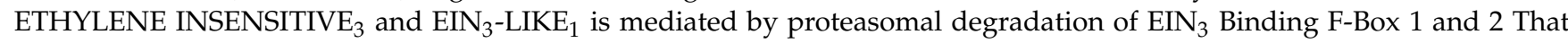
Requires $\mathrm{EIN}_{2}$ in Arabidopsis. Plant Cell 2010, 22, 2384-2401. [CrossRef]

51. Chen, H.; Xue, L.; Chintamanani, S.; Germain, H.; Lin, H.; Cui, H.; Cai, R.; Zuo, J.; Tang, X.; Li, X.; et al. Ethylene INSENSITIVE 3 and ETHYLENE INSENSITIVE 3 -LIKE1 repress SALICYLIC ACID INDUCTION DEFICIENT 2 expression to negatively regulate plant innate immunity in Arabidopsis. Plant Cell 2009, 21, 2527-2540. [CrossRef] [PubMed]

52. Hwang, I.; Sheen, J. Two-component circuitry in Arabidopsis cytokinin signal transduction. Nature 2001, 413, 383-389. [CrossRef] [PubMed] 
53. Agarwal, P.; Reddy, M.P.; Chikara, J. WRKY: Its structure, evolutionary relationship, DNA-Binding selectivity, role in stress tolerance and development of plants. Mol. Biol. Rep. 2010, 38, 3883-3896. [CrossRef] [PubMed]

54. Faris, J.D.; Zhang, Z.; Lu, H.; Lu, S.; Reddy, L.; Cloutier, S.; Fellers, J.P.; Meinhardt, S.W.; Rasmussen, J.B.; Xu, S.S.; et al. A unique wheat disease resistance-like gene governs effector-triggered susceptibility to necrotrophic pathogens. Proc. Natl. Acad. Sci. USA 2010, 107, 13544-13549. [CrossRef] [PubMed]

55. Pandelova, I.; Melania, B.F.; Manning, V.A.; Wilhelm, L.J.; Mockler, T.C.; Ciuffetti, L.M. Analysis of transcriptome changes induced by Ptr ToxA in wheat provides insights into the mechanisms of plant susceptibility. Mol. Plant 2009, 2, 1067-1083. [CrossRef]

56. He, P.; Chintamanani, S.; Chen, Z.; Zhu, L.; Kunkel, B.N.; Alfano, J.R.; Tang, X.; Zhou, J.M. Activation of a COI1-dependent pathway in Arabidopsis by Pseudomonas syringae type III effectors and coronatine. Plant J. 2004, 37, 589-602. [CrossRef] [PubMed]

57. Wi, S.J.; Ji, N.R.; Park, K.Y. Synergistic biosynthesis of biphasic ethylene and reactive oxygen species in response to hemibiotrophic Phytophthora parasitica in tobacco plants. Physiol. Plant 2012, 159, 251-265. [CrossRef]

58. Yang, C.; Li, W.; Cao, J.; Meng, F.; Yu, Y.; Huang, J.; Jiang, L.; Liu, M.; Zhang, Z.; Chen, X.; et al. Activation of ethylene signaling pathways enhances disease resistance by regulating ROS and phytoalexin production in rice. Plant J. 2017, 89, 338-353. [CrossRef]

59. Rodrigues, F.C.T.; Aucique-P'erez, C.E.; Fontes, B.A.; Ribeiro, D.M.; Rodrigues, F.A. Involvement of ethylene in wheat resistance to infection by Pyricularia oryzae. Physiol. Mol. Plant Pathol. 2020, 112, 101526. [CrossRef]

60. Broekaert, W.F.; Delaure, S.L.; De Bolle, M.F.; Cammue, B.P. The role of ethylene in host-pathogen interactions. Annu. Rev. Phytopathol. 2006, 44, 393-416. [CrossRef]

61. Van Loon, L.C.; Geraats, B.P.; Linthorst, H.J. Ethylene as a modulator of disease resistance in plants. Trends Plant Sci. 2006, 11, 184-191. [CrossRef] [PubMed]

62. Bouchez, O.; Huard, C.; Lorrain, S.; Roby, D.; Balague, C. Ethylene is one of the key elements for cell death and defense response control in the Arabidopsis lesion mimic mutant vad1. Plant Physiol. 2007, 145, 465-477. [CrossRef] [PubMed]

63. Zermiani, M.; Zonin, E.; Nonis, A.; Begheldo, M.; Ceccato, L.; Vezzaro, A.; Baldan, B.; Trentin, A.; Masi, A.; Pegoraro, M.; et al. Ethylene negatively regulates transcript abundance of ROP-GAP rheostat-encoding genes and affects apoplastic reactive oxygen species homeostasis in epicarps of cold stored apple fruits. J. Exp. Bot. 2015, 8, 7255-7270. [CrossRef] [PubMed]

64. Belozerskaya, T.A.; Gessler, N.N. Oxidative stress and differentiation in Neurospora crassa. Microbiology 2006, 75, 427-431. [CrossRef]

65. Barna, B.; Fodor, J.; Harrach, B.D.; Pogány, M.; Király, Z. The Janus face of reactive oxygen species in resistance and susceptibility of plants to necrotrophic and biotrophic pathogens. Plant Physiol. Biochem. 2012, 59, 37-43. [CrossRef]

66. Mittler, R.; Vanderauwera, S.; Suzuki, N.; Miller, G.; Tognetti, V.B.; Vandepoele, K.; Gollery, M.; Shulaev, V.; van Breusegem, F. ROS signaling: The new wave? Trends Plant Sci. 2011, 16, 300-309. [CrossRef]

67. Yoshioka, H.; Sugie, K.; Park, H.J.; Maeda, H.; Tsuda, N.; Kawakita, K.; Doke, N. Induction of plant gp91 phox homolog by fungal cell wall, arachidonic acid, and salicylic acid in potato. Mol. Plant Microbe Interact. 2001, 14, 725-736. [CrossRef]

68. Xie, Y.J.; Xu, S.; Han, B.; Wu, M.Z.; Yuan, X.X.; Han, Y.; Gu, Q.; Xu, D.K.; Yang, Q.; Shen, W.B. Evidence of Arabidopsis salt acclimation induced by upregulation of HY1 and the regulatory role of RbohD-derived reactive oxygen species synthesis. Plant $J$. 2011, 66, 280-292. [CrossRef]

69. Mur, L.A.; Laarhoven, L.J.; Harren, F.J.; Hall, M.A.; Smith, A.R. Nitric oxide interacts with salicylate to regulate biphasic ethylene production during the hypersensitive response. Plant Physiol. 2008, 148, 1537-1546. [CrossRef]

70. Ding, L.; Xu, H.; Yi, H.; Yang, L.; Kong, Z.; Zhang, L.; Xue, S.; Jia, H.; Ma, Z. Resistance to hemi-biotrophic F. graminearum infection is associated with coordinated and ordered expression of diverse defense signaling pathways. PLoS ONE 2011, 6, e19008. [CrossRef]

71. Xia, X.-J.; Zhou, Y.-H.; Shi, K.; Zhou, J.; Foyer, C.H.; Yu, J.-Q. Interplay between reactive oxygen species and hormones in the control of plant development and stress tolerance. J. Exp. Bot. 2015, 66, 2839-2856. [CrossRef] [PubMed]

72. Mlejnek, P.; Doležel, P.; Procházka, S. Intracellular phosphorylation of benzyladenosine is related to apoptosis induction in tobacco BY-2 cells. Plant Cell Environ. 2003, 26, 1723-1735. [CrossRef]

73. Daudi, A.; Cheng, Z.; O’Brien, J.A.; Mammarella, N.; Khan, S.; Ausubel, F.M.; Bolwell, P. The apoplastic oxidative burst peroxidase in Arabidopsis is a major component of pattern-triggered immunity. Plant Cell 2012, 24, 275-287. [CrossRef] [PubMed]

74. Bolwell, P.P.; Page, A.; Pi'slewska, M.; Wojtaszek, P. Pathogenic infection and the oxidative defences in plant apoplast. Protoplasma 2001, 217, 20-32. [CrossRef] [PubMed]

75. Dmochowska-Boguta, M.; Nadolska-Orczyk, A.; Orczyk, W. Roles of peroxidases and NADPH oxidases in the oxidative response of wheat (Triticum aestivum) to brown rust (Puccinia triticina) infection. Plant Pathol. 2013, 62, 993-1002. [CrossRef]

76. Torres, M.A.; Dangl, J.L.; Jones, J.D. Arabidopsis gp91phox homologues AtrbohD and AtrbohF are required for accumulation of reactive oxygen intermediates in the plant defense response. Proc. Natl. Acad. Sci. USA 2002, 99, 517-522. [CrossRef]

77. Chaouch, S.; Queval, G.; Noctor, G. AtRbohF is a crucial modulator of defence-associated metabolism and a key factor in the interplay between intracellular oxidative stress and pathogenesis responses in Arabidopsis. Plant J. 2012, 69, 613-627. [CrossRef]

78. Torres, M.A.; Jones, J.D.G.; Dangl, J.L. Pathogen-induced, NADPHoxidase derived reactive oxygen intermediates suppress spread of celldeath in Arabidopsis thaliana. Nat. Genet. 2005, 37, 1130-1134. [CrossRef]

79. Mersmann, S.; Bourdais, G.; Rietz, S.; Robatzek, S. Ethylene signaling regulates accumulation of the FLS2 receptor and is required for the oxidative burst contributing to plant immunity. Plant Physiol. 2010, 154, 391-400. [CrossRef] 
80. Almagro, L.; Gomez Ros, L.V.; Belchi-Navarro, S.; Bru, R.; Ros Barcello, A.; Pedreno, M.A. Class III peroxidases in plant defence reactions. J. Exp. Bot. 2009, 60, 377-390. [CrossRef]

81. Golemiec, E.; Tokarz, K.; Wielanek, M.; Niewiadomska, E. A dissection of the effects of ethylene, $\mathrm{H}_{2} \mathrm{O}_{2}$ and high irradiance on antioxidants and several genes associated with stress and senescence in tobacco leaves. J. Plant Physiol. 2014, 171, 269-275. [CrossRef] [PubMed]

82. Ma, Y.; Yang, M.; Wang, J.; Jiang, C.-Z.; Wang, Q. Application of exogenous ethylene inhibits postharvest peel browning of 'Huangguan' pear. Front. Plant Sci. 2017, 7, e2029. [CrossRef] [PubMed]

83. Argandona, V.H.; Chaman, M.; Cardemil, L.; Munoz, O.; Zúniga, G.E.; Corcuera, L.J. Ethylene production and peroxidase activity in aphid-infested barley. J. Chem. Ecol. 2001, 27, 53-68. [CrossRef] [PubMed]

84. He, J.; Yue, X.; Wang, R.; Zhang, Y. Ethylene mediates UV-B-induced stomatal closure via peroxidase-dependent hydrogen peroxide synthesis in Vicia faba (L.). J. Exp. Bot. 2011, 62, 2657-2666. [CrossRef]

85. Maksimov, I.V.; Yarullina, L.G.; Burkhanova, G.F.; Zaikina, E.A. Relationship between the aggressiveness and catalase activity of Septoria nodorum Berk. in wheat. Biol. Bull. 2013, 40, 441-446. [CrossRef]

86. Sewelam, N.; Kazan, K.; Thomas-Hall, S.R.; Kidd, B.N.; Manners, J.M.; Schenk, P.M. Ethylene response factor 6 is a regulator of reactive oxygen species signaling in Arabidopsis. PLOS ONE 2013, 8, e70289. [CrossRef]

87. Metraux, J.P. Systemic acquired resistance and salicylic acid: Current state of knowledge. Eur. J. Plant Pathol. 2001, 107, 13-18. [CrossRef]

88. Jiang, C.J.; Shimono, M.; Sugano, S.; Kojima, M.; Liu, X.; Inoue, H.; Sakakibara, H.; Takatsuji, H. Cytokinins act synergistically with salicylic acid to activate defense gene expression in rice. Mol. Plant Microbe Interact. 2013, 3, 287-296. [CrossRef]

89. Naseem, M.; Kaltdorf, M.; Dandekar, T. The nexus between growth and defence signalling: Auxin and cytokinin modulate plant immune response pathways. J. Exp. Bot. 2015, 66, 4885-4896. [CrossRef]

90. Bielach, A.; Hrtyan, M.; Tognetti, V.B. Plants under Stress: Involvement of auxin and cytokinin. Int. J. Mol. Sci. 2017, 18, 1427. [CrossRef]

91. Wybouw, B.; De Rybe, B. Cytokinin-A developing story. Trends Plant Sci. 2019, 24, 2. [CrossRef]

92. Walters, D.R.; McRoberts, N. Plants and biotrophs: A pivotal role for cytokinins? Trends Plant Sci. 2006, 11, 581-586. [CrossRef] [PubMed]

93. Igari, K.; Endo, S.; Hibara, K.I.; Aida, M.; Sakakibara, H.; Kawasaki, T.; Tasaka, M. Constitutive activation of a CC-NB-LRR protein alters Growth-defense nexus: Auxin and cytokinin crosstalk morphogenesis through the cytokinin pathway in Arabidopsis. Plant J. 2008, 55, 14-27. [CrossRef]

94. Babosha, A.V. Regulation of resistance and susceptibility in wheatpowdery mildew pathosystem with exogenous cytokinins. $J$. Plant Physiol. 2009, 166, 1892-1903. [CrossRef] [PubMed]

95. Grosskinsky, D.K.; Naseem, M.; Abdelmohsen, U.R.; Plickert, N.; Engelke, T.; Griebel, T.; Zeier, J.; Novak, O.; Strnad, M.; Pfeifhofer, H.; et al. Cytokinins mediate resistance against Pseudomonas syringae in tobacco through increased antimicrobial phytoalexin synthesis independent of salicylic acid signalling. Plant Physiol. 2011, 157, 815-830. [CrossRef] [PubMed]

96. Marmath, K.K.; Giri, P.; Taj, G.; Pandey, D.; Kumar, A. Effect of zeatin on the infection process and expression of MAPK-4 during pathogenesis of Alternaria brassicae in non-host and host Brassica plants. Afr. J. Biotechnol. 2013, 12, 2164-2174. [CrossRef]

97. Reusche, M.; Klásková, J.; Thole, K.; Truskina, J.; Novák, O.; Janz, D.; Strnad, M.; Spíchal, L.; Lipka, V.; Teichman, T. Stabilization of cytokinin levels enhances arabidopsis resistance against Verticillium longisporum. Mol. Plant Microbe Interact. 2013, 26, 850-860. [CrossRef]

98. Spoustová, P.; Hýsková, V.; Müller, K.; Schnablová, R.; Ryšlavá, H.; Čeřovská, N.; Malbeck, J.; Cvikrová, M.; Synková, H. Tobacco susceptibility to Potato virus $\mathrm{Y}(\mathrm{NTN})$ infection is affected by grafting and endogenous cytokinin content. Plant Sci. 2015, 235, 25-36. [CrossRef]

99. Chang, H.; Jones, M.L.; Banowetz, G.M.; Clark, D.G. Overproduction of cytokinins in petunia flwers transformed with PSAG12IPT delays corolla senescence and decreases sensitivity to ethylene. Plant Physiol. 2003, 132, 2174-2183. [CrossRef]

100. Zdarska, M.; Dobisová, T.; Gelová, Z.; Pernisová, M.; Dabravolski, S.; Hejátko, J. Illuminating light, cytokinin, and ethylene signalling crosstalk in plant development. J. Exp. Bot. 2015, 66, 4913-4931. [CrossRef] [PubMed]

101. Korobova, A.V.; Vysotskaya, L.B.; Vasinskaya, A.N.; Kudoyarova, G.R.; Kuluev, B.R.; Veselov, S.Y. Dependence of root biomass accumulation on the content and metabolism of cytokinins in ethylene-insensitive plants. Russ. J. Plant Physiol. 2016, 63, 597-603. [CrossRef]

102. Naseem, M.; Dandekar, T. The role of auxin-cytokinin antagonism in plant-pathogen interactions. PLoS Pathog. 2012, 8, e1003026. [CrossRef] [PubMed]

103. Wan, L.; Koeck, M.; Williams, S.J.; Ashton, A.R.; Lawrence, G.J.; Sakakibara, H.; Kojima, M.; Böttcher, C.; Ericsson, D.J.; Hardham, A.R.; et al. Structural and functional insights into the modulation of the activity of a flax cytokinin oxidase by flax rust effector AvrL567-A. Mol. Plant Pathol. 2019, 20, 211-222. [CrossRef] [PubMed]

104. Avalbaev, A.M.; Somov, K.A.; Yuldashev, R.A.; Shakirova, F.M. Cytokinin oxidase is key enzyme of cytokinin degradation. Biochemistry 2012, 77, 1354-1361. [CrossRef]

105. Xu, J.; Chen, L.; Sun, H.; Wusiman, N.; Sun, W.; Li, B.; Gao, Y.; Kong, J.; Zhang, D.; Zhang, X.; et al. Crosstalk between cytokinin and ethylene signaling pathways regulates leaf abscission in cotton in response to chemical defoliants. J. Exp. Bot. 2019, 70, 1525-1538. [CrossRef] 
106. Hai, N.N.; Chuong, N.N.; Tu, N.H.C.; Kisiala, A.; Hoang, X.L.T.; Thao, N.P. Role and regulation of cytokinins in plant response to drought stress. Plants 2020, 9, 422. [CrossRef]

107. Taverner, E.; Lethama, D.S.; Wanga, J.; Cornishb, E.; Willcocks, D.A. Influence of ethylene on cytokinin metabolism in relation to Petunia corolla senescence. Phytochemistry 1999, 51, 341-347. [CrossRef]

108. Hass, C.; Lohrmann, J.; Albrecht, V.; Sweere, U.; Humme, F.; Yoo, S.D.; Hwang, I.; Zhu, T.; Schafer, E.; Kudla, J.; et al. The response regulator 2 mediates ethylene signalling and hormone signal integration in Arabidopsis. EMBO J. 2004, 23, 3290-3302. [CrossRef]

109. Shi, Y.; Tian, S.; Hou, L.; Huang, X.; Zhang, X.; Guo, H.; Yang, S. Ethylene signaling negatively regulates freezing tolerance by repressing expression of CBF and Type-A ARR genes in Arabidopsis. Plant Cell 2012, 24, 2578-2595. [CrossRef]

110. Zdarska, M.; Cuyacot, A.R.; Tarr, P.T.; Yamoune, A.; Szmitkowska, A.; Hrdinova, V.; Gelova, Z.; Meyerowitz, E.M.; Hejatko, J. ETR1 Integrates response to ethylene and cytokinins into a single multistep phosphorelay pathway to control root growth. Mol. Plant 2019, 12, 1338-1352. [CrossRef]

111. Huo, R.; Liu, Z.; Yu, X.; Li, Z. The interaction network and signaling specificity of two-component system in Arabidopsis. Int. J. Mol. Sci. 2020, 21, 4898. [CrossRef] [PubMed]

112. Zubo, Y.O.G.; Schaller, E. Role of the cytokinin-activated Type-B response regulators in hormone crosstalk. Plants 2020, 9, 166. [CrossRef] [PubMed]

113. Choi, J.; Choi, D.; Lee, S.; Ryu, C.M.; Hwang, I. Cytokinins and plant immunity: Old foes or new friends? Trends Plant Sci. 2011, 7, 388-394. [CrossRef] [PubMed]

114. Naseem, M.; Wölflng, M.; Dandekar, T. Cytokinins for immunity beyond growth, galls and green islands. Trends Plant Sci. 2014, 19, 481-484. [CrossRef] [PubMed]

115. Rashotte, A.M.; Carson, S.D.B.; To, J.P.C.; Kieber, J.J. Expression profiling of cytokinin action in arabidopsis. Plant Physiol. 2003, 132, 1998-2011. [CrossRef] [PubMed]

116. Lee, D.J.; Park, J.-Y.; Ku, S.-J.; Ha, Y.-M.; Kim, S.; Kim, M.D.; Oh, M.-H.; Kim, J. Genome-wide expression profiling of ARABIDOPSIS RESPONSE REGULATOR 7 (ARR7) overexpression in cytokinin response. Mol. Genet. Genom. 2007, 277, 115-137. [CrossRef] [PubMed]

117. Qiu, D.; Xiao, J.; Ding, X.; Xiong, M.; Cai, M.; Cao, Y.; Li, X.; Xu, C.; Wang, S. OsWRKY13 mediates rice disease resistance by regulating defense-related genes in salicylate- and jasmonate-dependent signaling. Mol. Plant Microbe Interact. 2007, 20, 492-499. [CrossRef] 